\title{
Modeling the vertical soil organic matter profile using Bayesian parameter estimation
}

\author{
M. C. Braakhekke ${ }^{1,2,3}$, T. Wutzler ${ }^{1}$, C. Beer ${ }^{1}$, J. Kattge ${ }^{1}$, M. Schrumpf ${ }^{1}$, B. Ahrens ${ }^{1}$, I. Schöning ${ }^{1}$, M. R. Hoosbeek ${ }^{2}$, \\ B. Kruijt ${ }^{2}$, P. Kabat ${ }^{2}$, and M. Reichstein ${ }^{1}$ \\ ${ }^{1}$ Max Planck Institute for Biogeochemistry, P.O. Box 100164, 07701 Jena, Germany \\ ${ }^{2}$ Wageningen University, Department of Environmental Sciences, Earth System Science and Climate Change Group, \\ P.O. Box 47, 6700AA Wageningen, the Netherlands \\ ${ }^{3}$ International Max Planck Research School on Earth System Modelling, Hamburg, Germany \\ Correspondence to: M. C. Braakhekke (maarten.braakhekke@bgc-jena.mpg.de)
}

Received: 29 May 2012 - Published in Biogeosciences Discuss.: 21 August 2012

Revised: 7 December 2012 - Accepted: 20 December 2012 - Published: 24 January 2013

\begin{abstract}
The vertical distribution of soil organic matter (SOM) in the profile may constitute an important factor for soil carbon cycling. However, the formation of the SOM profile is currently poorly understood due to equifinality, caused by the entanglement of several processes: input from roots, mixing due to bioturbation, and organic matter leaching. In this study we quantified the contribution of these three processes using Bayesian parameter estimation for the mechanistic SOM profile model SOMPROF. Based on organic carbon measurements, 13 parameters related to decomposition and transport of organic matter were estimated for two temperate forest soils: an Arenosol with a mor humus form (Loobos, the Netherlands), and a Cambisol with mull-type humus (Hainich, Germany). Furthermore, the use of the radioisotope ${ }^{210} \mathrm{~Pb}_{\mathrm{ex}}$ as tracer for vertical SOM transport was studied. For Loobos, the calibration results demonstrate the importance of organic matter transport with the liquid phase for shaping the vertical SOM profile, while the effects of bioturbation are generally negligible. These results are in good agreement with expectations given in situ conditions. For Hainich, the calibration offered three distinct explanations for the observations (three modes in the posterior distribution). With the addition of ${ }^{210} \mathrm{~Pb}_{\mathrm{ex}}$ data and prior knowledge, as well as additional information about in situ conditions, we were able to identify the most likely explanation, which indicated that root litter input is a dominant process for the SOM profile. For both sites the organic matter appears to comprise mainly adsorbed but potentially leachable material, pointing to the importance of organo-mineral interactions. Furthermore, or-
\end{abstract}

ganic matter in the mineral soil appears to be mainly derived from root litter, supporting previous studies that highlighted the importance of root input for soil carbon sequestration. The ${ }^{210} \mathrm{~Pb}_{\mathrm{ex}}$ measurements added only slight additional constraint on the estimated parameters. However, with sufficient replicate measurements and possibly in combination with other tracers, this isotope may still hold value as tracer for SOM transport.

\section{Introduction}

The current lack of understanding of the soil system forms an important contribution to the uncertainty of terrestrial carbon cycle predictions (Heimann and Reichstein, 2008; Trumbore, 2009). To improve simulation of soil carbon cycling, it is necessary to move beyond the simple description of organic matter decomposition that is currently being applied in most large-scale models (Reichstein and Beer, 2008). Increasing evidence indicates that decomposition and stabilization are controlled by a range of mechanisms that depend on physical, chemical, and biological factors (von Lützow et al., 2006). These factors vary laterally at landscape scale in relation to climate, vegetation and soil type. In the vertical dimension, however, they change on a scale of centimeters to meters, since most drivers (e.g., wetting, heating, organic matter input) are exerted on the soil at or near the surface, propagating downwards. Consequently, the conditions that determine soil carbon cycling are highly depth-dependent and different 
mechanisms may be operating in different layers within one profile (Rumpel et al., 2002; Salomé et al., 2010; Rumpel and Kögel-Knabner, 2011). Therefore, aggregation of processes and soil properties over the profile, or downward extrapolation of topsoil organic carbon, as used in many soil organic matter (SOM) models (e.g., Parton et al., 1987; Tuomi et al., 2009), is likely an oversimplification, inadequate to support new parameterizations of relevant processes.

Awareness of this problem has spurred recent efforts to develop models that predict the vertical distribution of SOM, based on explicit descriptions of carbon deposition processes in the profile (Jenkinson and Coleman, 2008; Koven et al., 2009; Braakhekke et al., 2011). In most soils there are three mechanisms by which organic carbon can be input at any given depth: (i) organic matter may be deposited in situ by root exudation, sloughing off of root tissue and root turnover. (ii) Organic matter is transferred within the profile due to movement with the liquid phase. This type of transport is of an advective nature, and affects only fractions that are potentially mobile: mainly dissolved, and to a lesser degree colloidal organic matter. (iii) Downward dispersal of organic matter occurs due to mixing of the soil matrix. Soil mixing is mostly caused by bioturbation - the reworking activity of soil animals and plant roots - and its effects on organic matter may be simulated mathematically as diffusion, provided the time and space scale of the model are sufficiently large (Boudreau, 1986; Braakhekke et al., 2011).

The processes involved in SOM deposition in the profile - root input, liquid phase transport, and bioturbation - are fundamentally different, not only in a physical and mathematical sense, but also in terms of their relationship with environmental factors. Therefore, in order for a SOM profile model to be robust over different ecosystems and soil types, and over changing environmental conditions, the relevant processes should be explicitly represented. Furthermore, the distribution of organic matter over particulate and potentially mobile fractions needs to be accounted for.

Unfortunately, the different processes have been poorly quantified to this date. Published results are inconsistent, and past studies have generally focused on a single mechanism, rather than comparing all three (Rasse et al., 2005; Kaiser and Guggenberger, 2000; Tonneijck and Jongmans, 2008). Their extremely low rates, as well as practical problems, impede direct measurements of these processes in the field. Furthermore, the fact that the mechanisms are acting simultaneously complicates inference from SOM profile measurements. Diffusion and advection of decaying compounds, such as organic matter, can produce very similar concentration profiles, despite the different natures of these processes. Moreover, root input closely follows the root biomass distribution, which often strongly resembles the SOM profile. Hence, it is generally not possible to derive the rate of each process from the organic carbon profile alone, unless strong assumptions are made. A model that includes all relevant processes may be able to explain an observed soil carbon profile by several different mechanisms - a problem referred to as equifinality (Beven and Freer, 2001).

Thus, additional information is required in order to parameterize dynamic SOM profile models. In past studies, ${ }^{13} \mathrm{C}$ and ${ }^{14} \mathrm{C}$ have been used as tracers for this purpose (Elzein and Balesdent, 1995; Freier et al., 2010; Baisden et al., 2002). Although these isotopes are particularly useful for constraining organic matter turnover times and carbon pathways, their precise information content with respect to the processes involved in SOM profile formation is less clear, since root input leads to direct input of ${ }^{13} \mathrm{C}$ and ${ }^{14} \mathrm{C}$ at depth. In this context, fallout radio-isotopes (e.g., ${ }^{137} \mathrm{Cs},{ }^{134} \mathrm{Cs},{ }^{210} \mathrm{~Pb}$ ex,${ }^{7} \mathrm{Be}$ ) may be more effective. Such tracers have two major advantages over carbon isotopes: (i) loss occurs only due to radioactive decay, which is constant and exactly known; and (ii) input occurs only at the soil surface - direct input at depth is negligible. These points imply that the vertical transport rate of such isotopes can be directly inferred from their concentration profiles (Kaste et al., 2007; He and Walling, 1997). Since many radio-isotopes sorb strongly to organic matter molecules, they offer an effective alternative or complement to carbon isotopes for inferring organic matter transport rates in soils (Dörr and Münnich, 1989, 1991). Particularly ${ }^{210} \mathrm{~Pb}_{\mathrm{ex}}$ $\left({ }^{210} \mathrm{~Pb}\right.$ in excess of the in situ produced fraction) is a valuable tracer due to its strong adsorption to soil particles, and relatively constant fallout rate (Walling and He, 1999). Past studies have mostly used radio-isotopes for determining erosion and deposition rates (Mabit et al., 2009; Wakiyama et al., 2010), while their use for inferring vertical transport at stable sites has received little attention (Dörr and Münnich, 1989; Kaste et al., 2007; Arai and Tokuchi, 2010; Yoo et al., 2011).

The aim of this study is to examine SOM profile formation with model inversion. We used ${ }^{210} \mathrm{~Pb}_{\mathrm{ex}}$ concentration profiles, in addition to soil carbon measurements, to calibrate the model SOMPROF (Braakhekke et al., 2011) for two forest sites with contrasting SOM profiles. SOMPROF is a vertically explicit SOM model that simulates the distribution of organic matter over the mineral soil profile and surface organic layers. The aim of the model is to represent SOM profile formation over time scales of years to centuries. It includes simple but explicit representations of the relevant processes: bioturbation, liquid phase transport, root litter input, and decomposition. SOMPROF was developed with largescale application in an earth system model in mind. It was shown to be able to produce SOM profiles that compare well to observations (Braakhekke et al., 2011), but parameter sets for different soils and ecosystems have hitherto not been derived.

For both sites, 13 SOMPROF parameters were estimated. We focused on unmeasurable parameters such as decomposition rate coefficients and organic matter transport rates. The model inversion was performed in a Bayesian framework, allowing prior knowledge of the model parameters to be included and to estimate their posterior uncertainty. In view of the limited understanding of the SOM profile, the aim of this 


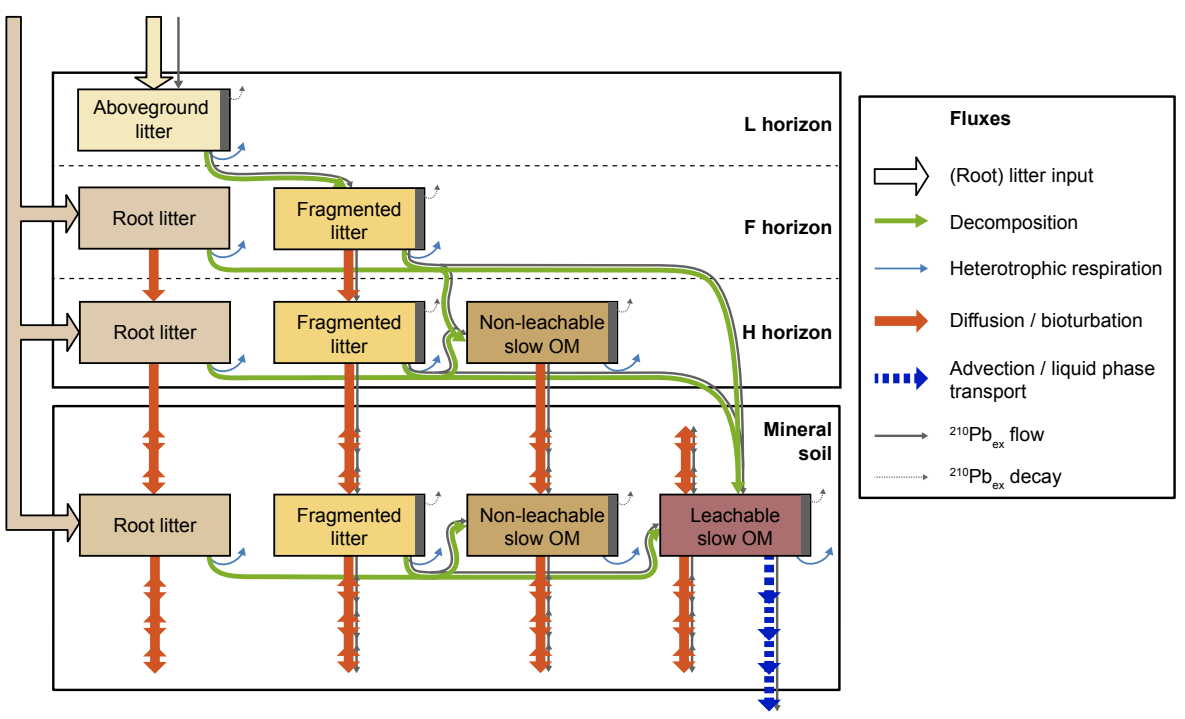

Fig. 1. Overview of the SOMPROF model and the ${ }^{210} \mathrm{~Pb}_{\mathrm{ex}}$ module. The dark gray rectangles indicate ${ }^{210} \mathrm{~Pb}$ ex associated with the organic matter pools.

study went beyond simply reducing the uncertainty ranges of the parameters. We also sought to gain qualitative understanding of the model's behavior, specifically its potential ability to explain observations by different mechanisms, and the value of ${ }^{210} \mathrm{~Pb}_{\mathrm{ex}}$ data and prior knowledge to improve parameter identification. This work also represents a first step towards testing the validity of SOMPROF for different soils and ecosystems.

We aim to answer the following questions: (i) what is the relative importance of the different processes involved in SOM profile formation? (ii) How much organic matter is present as material potentially transportable with the liquid phase, as compared to immobile particulate material? And, (iii) are ${ }^{210} \mathrm{~Pb}_{\mathrm{ex}}$ profile measurements useful for constraining the model parameters?

\section{Methods}

\subsection{The SOMPROF model}

Here a brief overview of the SOMPROF model is presented. We focus specifically on the model equations in which the estimated parameters are applied, and the ${ }^{210} \mathrm{~Pb}_{\text {ex }}$ module. A more exhaustive description and the rationale behind the model structure is presented in Braakhekke et al. (2011).

In SOMPROF the soil profile is divided into the mineral soil and the surface organic layer, which is assumed to contain no mineral material and is further subdivided into three horizons: L, F and $\mathrm{H}$ (Fig. 1). These organic horizons are simulated as homogeneous connected reservoirs of organic matter $(\mathrm{OM})$. Decomposition products of litter generally flow from the $\mathrm{L}$ to the $\mathrm{F}$ horizon and from the $\mathrm{F}$ to the $\mathrm{H}$ hori- zon. Additionally, material may be transported downward between the organic horizons and into the mineral soil by bioturbation. For the mineral soil, which comprises both organic matter and mineral material, the model simulates the vertical distribution of the organic matter pools, with a diffusionadvection model.

In view of the low rates of the relevant processes, and lack of knowledge of initial conditions at the sites, the SOMPROF simulations in this study covered the complete period of SOM profile formation, starting without any organic carbon in the profile. The model was run with a time step length of one month $(1 / 12 \mathrm{yr})$, for a specified maximum number of years, depending on the age and history of the site, and was driven by repeated annual cycles of measured or estimated soil temperature, moisture and (root) litter production. The main reason for considering temperature and moisture was to remove effects of local climate from the estimated decomposition rate coefficients, which thus are more intrinsic quantities, influenced mostly by local soil and vegetation properties. Furthermore, seasonal fluctuations of the forcing variables were accounted for since the timing of oscillations may have effects on long time scales due to non-linear interactions in the model. We limited the forcing cycle to one year, because inter-annual variability is expected to be small compared to seasonal fluctuations and the available measurements were not sufficient to derive longer cycles.

\subsubsection{Organic matter pools and decomposition}

Organic matter simulated in SOMPROF comprises five pools (Fig. 1), representing fractions that differ with respect to decomposability, transport behavior and mechanism of input: aboveground litter (AGL), fragmented litter (FL), root litter 
(RL), non-leachable slow organic matter (NLS), and leachable slow organic matter (LS). Aboveground and root litter receive external input; fragmented litter and leachable and non-leachable slow OM are formed by decomposition. LS is absent in the organic horizons since the adsorptive capacity there is assumed to be negligible compared to that of the mineral soil.

Organic matter decomposition is simulated as a first-order decay flux, corrected for soil temperature and moisture. For any organic matter pool $i$, the decomposition flux $L_{i}$ is defined as:

$L_{i}=f(T) g(W) k_{i} C_{i}$,

where $C_{i}$ is the concentration $\left(\mathrm{kg} \mathrm{m}^{-3}\right.$, for the mineral soil) or the stock $\left(\mathrm{kg} \mathrm{m}^{-2}\right.$, for the organic horizons), $k_{i}$ the decomposition rate coefficient $\left(\mathrm{yr}^{-1}\right)$ at $10^{\circ} \mathrm{C}$ and optimal soil moisture, and $f(T)$ and $g(W)$ the response functions for soil temperature and moisture (see Braakhekke et al., 2011). To avoid errors due to smoothing of the temperature and moisture data to monthly values, the response factors were calculated for the unsmoothed, daily measurements. These response factors were subsequently averaged to monthly values, and several years of data were averaged to an average annual cycle, which was used to calculate the decomposition fluxes.

The formation of fragmented litter, non-leachable, and leachable slow OM is defined according to a transformation fraction $\left(\alpha_{i \rightarrow j}\right)$ that determines the decomposition flux $F_{i \rightarrow j}$ from donor pool $i$ to the receiving pool $j$ :

$F_{i \rightarrow j}=\alpha_{i \rightarrow j} L_{i}$.

The organic matter that does not flow to other pools is assumed to be lost as $\mathrm{CO}_{2}$.

For the calibration measured organic carbon amounts were always compared to total simulated organic carbon, summed over all pools. Mass fraction in the mineral soil layers was calculated as the organic carbon mass divided by the total mass (mineral plus organic) in each layer. Effective decomposition rate coefficients were determined by dividing the total simulated heterotrophic respiration by the total organic matter stock of the respective layers.

\subsubsection{Organic matter transport}

All organic matter pools except aboveground litter are transported by bioturbation at equal rate. Conversely, only the leachable slow organic matter pool is transported by liquid phase transport. All transport parameters are assumed constant and independent of depth, although the diffusivity of organic matter may vary with depth due to bulk density variations (see Eq. 4).

For the organic layer, organic matter transport due to bioturbation is determined by the bioturbation rate $B$ $\left(\mathrm{kg} \mathrm{m}^{-2} \mathrm{yr}^{-1}\right)$, which represents the mixing activity of the soil fauna, i.e., the amount of material being displaced per unit area and unit time. $B$ is the maximum flux of organic matter that can be moved to the next horizon. In case the potential bioturbation flux for one time step exceeds the amount of organic matter in a horizon, it is adjusted downward. For the mineral soil, a diffusion model is applied to simulate transport due to bioturbation:

$$
\left.\frac{\partial C_{i}}{\partial t}\right|_{\mathrm{BT}}=D_{\mathrm{BT}} \frac{\partial^{2} C_{i}}{\partial z^{2}},
$$

where $C_{i}$ is the local concentration of organic matter pool $i$ $\left(\mathrm{kg} \mathrm{m}^{-3}\right), z$ depth in the mineral soil (m, positive downward; $z=0$ at the top of the mineral soil), and $t$ time (yr). $D_{\mathrm{BT}}$ is the diffusivity $\left(\mathrm{m}^{2} \mathrm{yr}^{-1}\right)$, which is derived from the bioturbation rate according to mixing length theory, as follows (Braakhekke et al., 2011):

$$
D_{\mathrm{BT}}=\frac{1}{2} \frac{B}{\rho^{\mathrm{MS}}} l_{\mathrm{m}}
$$

where is $\rho^{\mathrm{MS}}$ is the local bulk density $\left(\mathrm{kg} \mathrm{m}^{-3}\right)$, which is depth dependent and can either be set to measured values or calculated by the model. $l_{\mathrm{m}}$ is the mixing length (m), which links the bioturbation rate to the diffusivity. The upper boundary condition, at the top of the mineral soil, is determined by the flux of material coming from the $H$ horizon.

Dissolved organic matter (DOM) is not explicitly represented in SOMPROF. Instead, the combined effects of adand desorption and water flow on the concentration profile of the leachable slow organic matter pool are simulated as an effective advection process:

$$
\left.\frac{\partial C_{\mathrm{LS}}}{\partial t}\right|_{\mathrm{LPT}}=-v \frac{\partial C_{\mathrm{LS}}}{\partial z}
$$

where $v$ is the effective organic matter advection rate $\left(\mathrm{m} \mathrm{yr}^{-1}\right)$. Note that the LS pool represents potentially leachable material; the bulk of this organic matter is in fact immobile due to adsorption to the mineral phase. Hence, the LS pool is also transportable by bioturbation.

The upper boundary condition for LS is determined by the total production in the organic layer. For all pools a zerogradient condition is used for the lower boundary. Hence, only advection of LS can lead to a loss of organic matter by transport.

\subsection{3 ${ }^{210} \mathrm{~Pb}_{\text {ex }}$ simulation}

${ }^{210} \mathrm{~Pb}$ is a radiogenic isotope that is input into the soil due to both atmospheric deposition and in situ formation within the profile. The fallout fraction $\left({ }^{210} \mathrm{~Pb}_{\mathrm{ex}}\right)$ is typically estimated as the difference between the total ${ }^{210} \mathrm{~Pb}$ activity and the activity of ${ }^{226} \mathrm{Ra}$, one of its precursors (Appleby and Oldfield, 1978).

A module has been added to SOMPROF in order to use measurements of ${ }^{210} \mathrm{~Pb}_{\mathrm{ex}}$ as a tracer for $\mathrm{SOM}$ transport 
(Fig. 1). The modeled ${ }^{210} \mathrm{~Pb}_{\text {ex }}$ concentration profile is controlled by atmospheric input, radioactive decay, and organic matter input, decomposition and transport. The ${ }^{210} \mathrm{~Pb}_{\mathrm{ex}}$ module is based on the following assumptions: (i) variations in time of the atmospheric ${ }^{210} \mathrm{~Pb}_{\mathrm{ex}}$ input are negligible; (ii) ${ }^{210} \mathrm{~Pb}_{\mathrm{ex}}$ is input only into the L horizon; (iii) once in the soil, ${ }^{210} \mathrm{~Pb}_{\mathrm{ex}}$ binds immediately and irreversibly to any organic matter pool; (iv) ${ }^{210} \mathrm{~Pb}_{\mathrm{ex}}$ "follows" the organic matter to which it is bound through the decomposition and transport processes; and (v) aside from transport, ${ }^{210} \mathrm{~Pb}_{\mathrm{ex}}$ is lost only due to radioactive decay, at a fixed rate of $0.0311 \mathrm{yr}^{-1}$.

Since ${ }^{210} \mathrm{~Pb}_{\mathrm{ex}}$ is only input into the $\mathrm{L}$ horizon, which contains no root litter, no ${ }^{210} \mathrm{~Pb}_{\mathrm{ex}}$ is associated with this pool. Furthermore, external input of organic matter as litter has a diluting effect on ${ }^{210} \mathrm{~Pb}_{\text {ex }}$, while loss of organic matter as $\mathrm{CO}_{2}$ leads to an increase of mass fraction. For the organic horizons, the ${ }^{210} \mathrm{~Pb}_{\mathrm{ex}}$ fluxes due to organic matter flow (either by transport or transformation to another pool) are calculated by multiplying the flux from a pool by its ${ }^{210} \mathrm{~Pb}_{\mathrm{ex}}$ mass fraction. For the mineral soil the transport equations are solved separately for ${ }^{210} \mathrm{~Pb}_{\mathrm{ex}}$ associated with the FL, NLS and LS pools.

Since the atmospheric deposition rate of ${ }^{210} \mathrm{~Pb}_{\mathrm{ex}}$ is not generally known, the ${ }^{210} \mathrm{~Pb}_{\mathrm{ex}}$ fractions were normalized relative to the fractions at the mineral soil surface for comparison with observations (see Sect. 2.3.2). Thus, the exact input rate is trivial, and was set to 1 . Mineral soil ${ }^{210} \mathrm{~Pb}_{\text {ex }}$ mass fractions, used for comparing with measurements, were calculated as the total ${ }^{210} \mathrm{~Pb}_{\mathrm{ex}}$ amount, summed over all organic matter pools, divided by the total mass (mineral plus organic).

\subsection{Site descriptions}

\subsubsection{Loobos}

Loobos is a Scots pine (Pinus sylvestris) forest on a well-drained, sandy soil in the Netherlands $\left(52^{\circ} 10^{\prime} 0^{\prime \prime} \mathrm{N}\right.$, $\left.5^{\circ} 44^{\prime} 38^{\prime \prime} \mathrm{E}\right)$. The climate is temperate/oceanic with an average annual precipitation of $966 \mathrm{~mm}$ and an average temperature of $10^{\circ} \mathrm{C}$ (WUR, Alterra, 2011). The area, which was originally covered by shifting sands, was planted with pine trees in the early 20th century. Currently, the forest floor is covered with a dense understorey of wavy hair grass (Deschampsia flexuosa) that roots primarily in the organic layer. Due to its young age, the soil is classified as Cambic or Haplic Arenosol (IUSS Working Group WRB, 2007; Smit, 1999) but shows clear signs of the onset of podzolization. Because of the high content of quartzitic sand (>94\%), the soil is very poor, which is reflected by a low $\mathrm{pH}(3-4)$ and nutrient concentrations, and a virtual absence of soil fauna (Emmer, 1995; Smit, 1999). Organic matter is comprised mostly of mor humus in a thick organic layer of circa $11 \mathrm{~cm}$, and organic carbon fractions in the mineral soil are very low.
Table 1. Model driving data and not-estimated parameters.

\begin{tabular}{lrrl}
\hline Variable/Parameter & Loobos & Hainich & Units \\
\hline Annual aboveground litter input & 0.310 & $0.314^{\mathrm{b}}$ & $\mathrm{kg} \mathrm{C} \mathrm{m}^{-2} \mathrm{yr}^{-1}$ \\
$\quad$ Canopy & 0.255 & $0.277^{\mathrm{b}}$ & \\
$\quad$ Understory & $0.055^{\mathrm{c}}$ & $0.037^{\mathrm{b}}$ & \\
Total annual root litter input & 0.543 & $0.178^{\mathrm{b}}$ & $\mathrm{kg} \mathrm{C} \mathrm{m}^{-2} \mathrm{yr}^{-1}$ \\
$\quad$ Canopy & 0.118 & $0.148^{\mathrm{b}}$ & \\
$\quad$ Understory & $0.425^{\mathrm{c}}$ & 0.03 & \\
Root litter distribution param. & $\mathrm{see}$ text & 7 & $\mathrm{~m}^{-1}$ \\
Soil temperature resp. param. & $308.56^{\mathrm{d}}$ & $308.56^{\mathrm{d}}$ & $\mathrm{K}$ \\
Soil moisture resp. param. $a^{\mathrm{e}}$ & 1 & 1 & - \\
Soil moisture resp. param. $b^{\mathrm{e}}$ & 20 & 20 & - \\
Soil temperature & $\mathrm{a}$ & $\mathrm{a}$ & $\mathrm{K}$ \\
Relative soil moisture content & $\mathrm{a}$ & $\mathrm{a}$ & - \\
Bulk density L layer & 50 & 50 & $\mathrm{~kg} \mathrm{~m}^{-3}$ \\
Bulk density F layer & 100 & 100 & $\mathrm{~kg} \mathrm{~m}^{-3}$ \\
Bulk density H layer & 150 & 150 & $\mathrm{~kg} \mathrm{~m}^{-3}$ \\
Bulk density mineral soil & 1400 & $\mathrm{a}$ & $\mathrm{kg} \mathrm{m}^{-3}$ \\
Simulation period & 95 & 1000 & $\mathrm{yr}^{-3}$ \\
Depth of bottom boundary & 2 & 0.7 & $\mathrm{~m}$ \\
\hline
\end{tabular}

${ }^{a}$ Variable in depth and/or time; ${ }^{b}$ Kutsch et al. (2010); W. Kutsch (personal communication, 2009); ${ }^{\mathrm{c}}$ Smit and Kooijman (2001); ${ }^{\mathrm{d}}$ Lloyd and Taylor (1994); ${ }^{\mathrm{e}}$ Soil moisture response function: $g(W)=\exp (-\exp (a-b W))$.

Half-hourly measurements of soil moisture and temperature were performed continuously at five depths $(5,13,30$, $60,110 \mathrm{~cm})$. Data for the period 1 May 2005 to 31 December 2008 were used to derive an average annual cycle of soil temperature and moisture, which was used for the simulations. Additionally, aboveground litter fall measurements on a two to four weeks basis for the period 2000 to 2008 were used to derive an average annual cycle for aboveground litter input. Since the carbon content of the litter was not determined, we used a fixed $\mathrm{C}$ fraction of $50 \%$. Bulk density was calculated by the model according to a function from Federer et al. (1993), based on hypothetical bulk densities of pure mineral and pure organic soil (set to 1400 and $150 \mathrm{~kg} \mathrm{~m}^{-3}$, respectively).

Annual root litter input for the understorey was taken from Smit and Kooijman (2001) (Table 1), who estimated root turnover in the same forest using root ingrowth cores. To account for seasonal fluctuations of the grass layer, the annual input of both above- and belowground grass litter was distributed over the year using a function based on data taken from Veresoglou and Fitter (1984), which peaks around early June. The vertical distribution of understorey root litter input was set such that approximately $95 \%$ occurs in the organic layer (Supplement Fig. 1), which corresponds to in situ observations of root biomass (A. Smit, personal communication, 2009). For the root litter input from the pine trees (Table 1), we used data from a forest in Belgium (Brasschaat) with a similar vegetation composition, soil type, and age (Janssens et al., 2002). The root litter input for Loobos was derived by scaling the estimate from the Janssens et al. (2002) study according to net primary productivity estimates of both sites, which were taken from Luyssaert 
et al. (2007). The root litter input from the canopy vegetation was held constant throughout the simulation. Its vertical distribution was also derived from information from Janssens et al. (2002), as well as personal communication from J. Elbers and I. Janssens (2009). At both the Brasschaat and Loobos sites, it is observed that the root biomass starts at the top of the $\mathrm{H}$ horizon and peaks at the mineral soil surface. Therefore, we chose a distribution function that increases linearly with depth from the top to the bottom of the $\mathrm{H}$ horizon. From there it decreases with depth according to a two-term exponential function: $f(z)=\exp (-20.00 z)+$ $0.0384 \exp (-0.886 z)$ (see Supplement Fig. 1). By this function we accounted for deep soil input from pine roots, which may be important for the vertical SOM profile. Since the thickness of the $H$ horizon is variable, the total distribution function was normalized at every time step.

The simulation length was set to $95 \mathrm{yr}$, which is the approximate time between the forest plantation and the sampling date. To account for the time needed for vegetation to develop, litter input was reduced in the initial stage, by multiplying with a function linearly increasing from 0 , at the start of the simulation, to 1, after $60 \mathrm{yr}$ (Emmer, 1995).

\subsubsection{Hainich}

This site is located in the Hainich national park in Central Germany, $\left(51^{\circ} 4^{\prime} 45.36^{\prime \prime} \mathrm{N}, 10^{\circ} 27^{\prime} 7.20^{\prime \prime} \mathrm{E}\right)$. The forest, which has been unmanaged for the last $60-70 \mathrm{yr}$, is dominated by beech (Fagus Sylvatica, 65\%) and ash (Fraxinus excelsior, $25 \%$ ) (Kutsch et al., 2010). The forest floor is covered by herbaceous vegetation (Allium ursinum, Mercurialis perennis, Anemone nemorosa), which peaks before canopy bud break. The climate is temperate suboceanic/subcontinental with an average annual precipitation of $800 \mathrm{~mm}$ and an average temperature of $7-8^{\circ} \mathrm{C}$.

The soil is classified as Luvisol or Cambisol (IUSS Working Group WRB, 2007; Kutsch et al., 2010). It has formed in limestone overlain by a layer of loess, and is characterized by a high clay content $(60 \%)$ and a $\mathrm{pH}$ of $\mathrm{H}_{2} \mathrm{O}$ of 5.9 to 7.8 (T. Persson, personal communication, 2011). The favorable soil properties support a high biological activity (Cesarz et al., 2007), corroborated by a thin organic layer and a welldeveloped A horizon. About $90 \%$ of the root biomass occurs above $40 \mathrm{~cm}$ depth. A similar distribution was used for the root litter input (Supplement Fig. 1).

The oldest trees at Hainich are approximately $250 \mathrm{yr}$ old, but presumably the site has been covered by similar vegetation for much longer. Thus, we assumed that the soil is close to steady state. Hence, a 1000yr simulation was used. For further information on the setup of the Hainich simulation, refer to the description of the reference simulation in Braakhekke et al. (2011). The model inputs that were not included in the calibration are listed in Table 1 .

\subsection{Observations used for the calibration}

\subsubsection{Organic carbon measurements}

For Loobos, measured carbon stocks in the L, F and $\mathrm{H}$ horizons and the mineral soil, and carbon mass fractions at 3 depths in the mineral profile were used in the calibration. Several profiles were affected by wind erosion; when this was the case, the affected measurements were omitted. In 2005 the soil was sampled in a regular quadratic grid at 25 points spaced $40 \mathrm{~m}$ apart. Organic layers were removed with a square metal frame with a side length of $25 \mathrm{~cm}$. The mineral soil was sampled horizon-wise with a Pürckhauer auger, 2 $3 \mathrm{~cm}$ wide and $1 \mathrm{~m}$ long. Soil samples were sieved to $<2 \mathrm{~mm}$ and ground. Carbon stocks in the organic layers were analyzed with a CN analyser Vario EL (Elementar Analysensysteme $\mathrm{GmbH}$, Hanau, Germany); carbon fractions in the mineral soil were measured with a CN Analyser VarioMax (Elementar Analysensysteme GmbH, Hanau, Germany). For the calibration the mineral soil carbon fractions from different samplings were interpolated to three fixed depth levels.

For Hainich, measured stocks in the $\mathrm{L}$ and $\mathrm{F} / \mathrm{H}$ horizon (the individual $F$ and $H$ horizons could not be identified) and in the mineral soil were used, as well as mass fraction measurements at 8 depths in the mineral profile. In addition, we used measured effective decomposition rate coefficients at $15^{\circ} \mathrm{C}$ and soil moisture at $60 \%$ of water holding capacity in the $\mathrm{L}$ and $\mathrm{F} / \mathrm{H}$ horizon, and at 7 depths in the mineral profile. The sampling procedure and organic carbon measurements are described in Schrumpf et al. (2011). The decomposition rate coefficients were calculated from measurements of respiration rates measured during lab incubation of soil samples, which is described in Kutsch et al. (2010). By dividing the average respiration rate of each sample by its organic carbon content, we obtained effective decomposition rate coefficients. All measurements are listed in Supplement Table 1.

Simulated organic carbon fractions and effective decomposition rate coefficients were interpolated to the measurement depths for comparing with measurements using piecewise Hermitian interpolation (Burden, 2004). Because organic carbon stocks and mass fractions cannot be less than zero and typically have large spatial variance, the measurements from replicate samplings can be assumed to have rightskewed distributions. We assumed that this is also the case for the effective decomposition rate measurements. Therefore, all measurements (and their corresponding model results) were $\log$ transformed for the calibration to bring the distributions closer to normal. This also reduced heteroscedasticity for the mineral soil organic carbon fractions.

\subsection{2 ${ }^{210} \mathrm{~Pb}_{\mathrm{ex}}$ measurements}

Since local ${ }^{210} \mathrm{~Pb}_{\text {ex }}$ measurements were not available for Loobos, we used two activity profiles from Kaste et al. (2007), for a site in the Hubbard Brook Experimental Forest, 


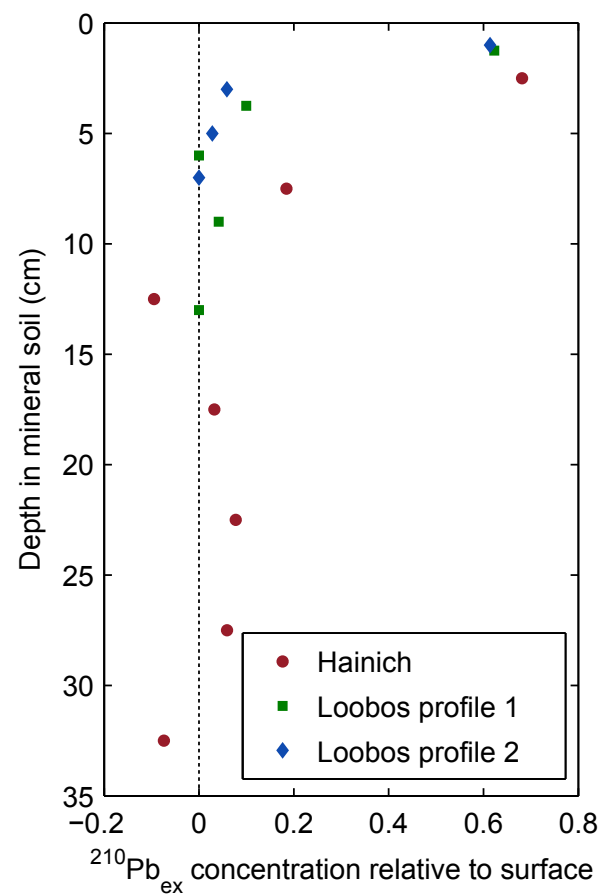

Fig. 2. Measured ${ }^{210} \mathrm{~Pb}_{\mathrm{ex}}$ concentrations used for the calibration. Concentrations are relative to the values at the surface. Note that the ${ }^{210} \mathrm{~Pb}_{\text {ex }}$ measurements for Loobos are taken from an equivalent site (Kaste et al., 2007).

New Hampshire, USA. This site has conditions similar to those at Loobos in terms of vegetation, soil texture, soil $\mathrm{pH}$, and soil biological activity (Bormann and Likens, 1994). Furthermore, pedological processes related to podzol formation are occurring at both sites. The two sites differ with respect to age, since the Loobos soil is very young. However, in view of the relatively fast decay rate of ${ }^{210} \mathrm{~Pb}$, and the shallow distribution of the ${ }^{210} \mathrm{~Pb}_{\text {ex }}$ profile (Fig. 2), we assume that it is close to steady state at both sites.

Local ${ }^{210} \mathrm{~Pb}_{\text {ex }}$ measurements at Hainich were performed for a study by Fujiyoshi and Sawamura (2004) (R. Fujiyoshi, personal communication, 2008). Although these measurements were corrected for in situ formed ${ }^{210} \mathrm{~Pb}$ by subtracting the ${ }^{226} \mathrm{Ra}$ activity (R. Fujiyoshi, personal communication, 2008), the activity profile did not approach zero with depth. Hence, this method did presumably not account for all supported ${ }^{210} \mathrm{~Pb}$. Therefore, we assumed that the ${ }^{210} \mathrm{~Pb}_{\mathrm{ex}}$ concentration is zero from approximately $12.5 \mathrm{~cm}$ downwards. The supported ${ }^{210} \mathrm{~Pb}$ activity was estimated as the average below this depth, and all data were corrected by subtracting this average. (Note that in several cases this produced negative concentrations.)

Only mineral soil ${ }^{210} \mathrm{~Pb}_{\mathrm{ex}}$ measurements were used in the calibration (Fig. 2 and Supplement Table 1). The profiles of both sites, as well as those predicted by the model, were normalized by dividing them by the ${ }^{210} \mathrm{~Pb}_{\mathrm{ex}}$ activity at the sur- face of the mineral soil, which was estimated using piecewise Hermitian extrapolation. Simulated ${ }^{210} \mathrm{~Pb}_{\mathrm{ex}}$ fractions and effective decomposition rate coefficients were interpolated to the measurement depths also using Hermitian interpolation, for comparing with measurements. Because of the negative observed values for Hainich, no log-transformations were used for the ${ }^{210} \mathrm{~Pb}_{\mathrm{ex}}$ data.

\subsection{Bayesian calibration}

We performed Bayesian estimation of 13 model parameters: five decomposition rate coefficients, five transformation fractions, and three transport parameters (Table 2). Bayesian calibration is aimed at deriving the posterior probability distribution $p(\boldsymbol{\theta} \mid \boldsymbol{O})$ of the model parameters $\boldsymbol{\theta}$ based on the misfit between the model results and the observations $\boldsymbol{O}$, and the a priori probability distribution of the parameters (Mosegaard and Sambridge, 2002). According to Bayes' theorem, the posterior distribution is defined as:

$p(\boldsymbol{\theta} \mid \boldsymbol{O})=c p(\boldsymbol{\theta}) p(\boldsymbol{O} \mid \boldsymbol{\theta})$,

where $p(\boldsymbol{\theta})$ is the prior probability distribution, expressing our knowledge of the parameters prior to the calibration, and $c$ is a normalization constant, ensuring that the integral over the distribution equals 1. $p(\boldsymbol{O} \mid \boldsymbol{\theta})$ is a likelihood function that expresses the probability of the observations $\boldsymbol{O}$, given the parameters $\boldsymbol{\theta}$ (Gelman et al., 2004, Chap. 1).

The calibrations were performed in three setups, in which ${ }^{210} \mathrm{~Pb}_{\text {ex }}$ data and prior knowledge were stepwise added, in order to investigate the information content of each source of information. For both sites, we ran calibrations in the following setups:

1. excluding ${ }^{210} \mathrm{~Pb}_{\mathrm{ex}}$ data and with weak priors;

2. including ${ }^{210} \mathrm{~Pb}_{\mathrm{ex}}$ data and with weak priors;

3. including ${ }^{210} \mathrm{~Pb}_{\mathrm{ex}}$ data and with strong priors.

Calibration setup 3 represents our best estimate of the model parameters.

\subsubsection{Likelihood function}

As discussed in Sect. 2.3, different types of observed variables were used in the calibration, referred to as "data streams". For any data stream $(i)$, the observations $\left(O_{i}\right)$ may be seen as the sum of the model prediction $\left(M_{i}(\theta)\right)$ plus a stochastic residual term $\left(\epsilon_{i}\right)$ :

$O_{i}=M_{i}(\boldsymbol{\theta})+\epsilon_{i}, \quad i=1,2 \ldots I$.

Note that for all data streams except ${ }^{210} \mathrm{~Pb}_{\mathrm{ex}}$ the model prediction and measurements were log-transformed. We assumed that the residuals are normally distributed with variance $\left(\sigma_{i}\right)$, which may be different for each data stream. The 
Table 2. The model parameters estimated in the calibration. Note that the prior distributions were only used for calibration setup 3 . The lower bound for all parameters is zero; the upper bound is given in the table.

\begin{tabular}{|c|c|c|c|c|}
\hline Parameter & Symbol & Units & $\begin{array}{l}\text { Prior distribution in } \\
\text { calibr. setup } 3\end{array}$ & Upper bound \\
\hline \multicolumn{5}{|c|}{ Decomposition rate coefficients at $10^{\circ} \mathrm{C}$ and optimal soil moisture } \\
\hline Aboveground litter & $k_{\mathrm{AGL}}$ & $\mathrm{yr}^{-1}$ & $\log -\mathcal{N}(-0.23,0.74)$ & 3 \\
\hline Root litter & $k_{\mathrm{RL}}$ & $\mathrm{yr}^{-1}$ & $\log -\mathcal{N}(-0.23,0.74)$ & 3 \\
\hline Fragmented litter & $k_{\mathrm{FL}}$ & $\mathrm{yr}^{-1}$ & $\log -\mathcal{N}(-0.23,0.74)$ & 3 \\
\hline $\begin{array}{l}\text { Non-leachable slow } \\
\text { organic matter }\end{array}$ & $k_{\mathrm{NLS}}$ & $\mathrm{yr}^{-1}$ & $\log -\mathcal{N}(-2.23,1.00)$ & 3 \\
\hline $\begin{array}{l}\text { Leachable slow } \\
\text { organic matter }\end{array}$ & $k_{\mathrm{LS}}$ & $\mathrm{yr}^{-1}$ & $\log -\mathcal{N}(-2.23,1.00)$ & 3 \\
\hline \multicolumn{5}{|c|}{ Transformation fractions } \\
\hline $\begin{array}{l}\text { Aboveground litter - } \\
\text { fragmented litter }\end{array}$ & $\alpha_{\mathrm{AGL} \rightarrow \mathrm{FL}}$ & - & Logit $-\mathcal{N}(0.43,0.95)$ & 1 \\
\hline $\begin{array}{l}\text { Fragmented litter - } \\
\text { non-leachable slow }\end{array}$ & $\alpha_{\mathrm{FL} \rightarrow \mathrm{NLS}}$ & - & Logit $-\mathcal{N}(-0.93,0.98)$ & $1,\left(1-\alpha_{\mathrm{FL} \rightarrow \mathrm{LS}}\right)$ \\
\hline $\begin{array}{l}\text { Fragmented litter - } \\
\text { leachable slow }\end{array}$ & $\alpha_{\mathrm{FL} \rightarrow \mathrm{LS}}$ & - & Logit $-\mathcal{N}(-0.93,0.98)$ & $1,\left(1-\alpha_{\mathrm{FL} \rightarrow \mathrm{NLS}}\right)$ \\
\hline $\begin{array}{l}\text { Root litter - non- } \\
\text { leachable slow }\end{array}$ & $\alpha_{\mathrm{RL} \rightarrow \mathrm{NLS}}$ & - & Logit $-\mathcal{N}(-0.93,0.98)$ & $1,\left(1-\alpha_{\mathrm{RL}} \rightarrow \mathrm{LS}\right)$ \\
\hline $\begin{array}{l}\text { Root litter - } \\
\text { leachable slow }\end{array}$ & $\alpha_{\mathrm{RL} \rightarrow \mathrm{LS}}$ & - & $\operatorname{Logit}-\mathcal{N}(-0.93,0.98)$ & $1,\left(1-\alpha_{\mathrm{RL}} \rightarrow \mathrm{NLS}\right)$ \\
\hline \multicolumn{5}{|c|}{ Transport parameters } \\
\hline Bioturbation rate & $B$ & $\begin{array}{l}\mathrm{kg} \mathrm{m}^{-2} \\
\mathrm{yr}^{-1}\end{array}$ & uniform & 3 \\
\hline Mixing length & $l_{\mathrm{m}}$ & $\mathrm{m}$ & uniform & 3 \\
\hline $\begin{array}{l}\text { Liquid phase transport } \\
\text { (advection) rate }\end{array}$ & $v$ & $\mathrm{~m} \mathrm{yr}^{-1}$ & uniform & 0.1 \\
\hline
\end{tabular}

conditional likelihood function for a given $\sigma_{i}$ is defined by the joint distribution of the residuals of all data streams:

$p\left(\boldsymbol{O} \mid \boldsymbol{\theta}, \boldsymbol{\sigma}^{\mathbf{2}}\right) \propto \prod_{i=1}^{I} \sigma_{i}^{-N_{i}} \exp \left(-\frac{1}{2 \sigma_{i}^{2}} S S_{i}(\boldsymbol{\theta})\right)$.

Note that we did not consider correlations between the different variables. $\operatorname{SS}_{i}(\boldsymbol{\theta})$ is the sum of squared residuals for data stream $(i)$ over all $\left(N_{i}\right)$ data points:

$S S_{i}(\boldsymbol{\theta})=\sum_{n=1}^{N_{i}}\left(O_{i, n}-M_{i, n}(\boldsymbol{\theta})\right)^{2}$.

Multiple replicate measurements, if available, were all individually included in $\mathrm{S}_{i}(\boldsymbol{\theta})$, meaning a single model prediction was compared to multiple observations. For the mineral soil profile, measurements from all depth levels were considered to be part of the same data stream; i.e., the residuals were assumed to have the same distribution.

The variance of the residuals $\left(\sigma_{i}^{2}\right)$ is usually determined by both model-related errors (deficiencies in the model struc- ture, errors in forcing data) as well as observational uncertainty (spatial heterogeneity, measurement errors). In some cases it may be estimated a priori based on knowledge of the model and the measurement uncertainty (Knorr and Kattge, 2005), but in general it must be considered unknown. For certain prior distributions $\sigma_{i}$ can be analytically integrated out of the joint likelihood function $p\left(\boldsymbol{O}, \boldsymbol{\sigma}^{2} \mid \boldsymbol{\theta}\right)$, yielding the marginal distribution ( $p(\boldsymbol{O} \mid \boldsymbol{\theta})$; Gelman et al., 2004, Chap. $3)$. We use the uninformative prior $p\left(\sigma_{i}\right) \propto 1 / \sigma_{i}$, which yields the following formulation of the likelihood function:

$p(\boldsymbol{O} \mid \boldsymbol{\theta}) \propto \prod_{i=1}^{I} S S_{i}(\boldsymbol{\theta})^{-N_{i} / 2}$.

\subsubsection{Prior parameter distributions}

We performed calibration with both strong and with weak prior distributions. For the runs with weak priors, the prior probability $P(\boldsymbol{\theta})$ was simply omitted from the posterior probability definition (Eq. 6), which resulted in a multivariate uniform distribution, within the sampling region. 

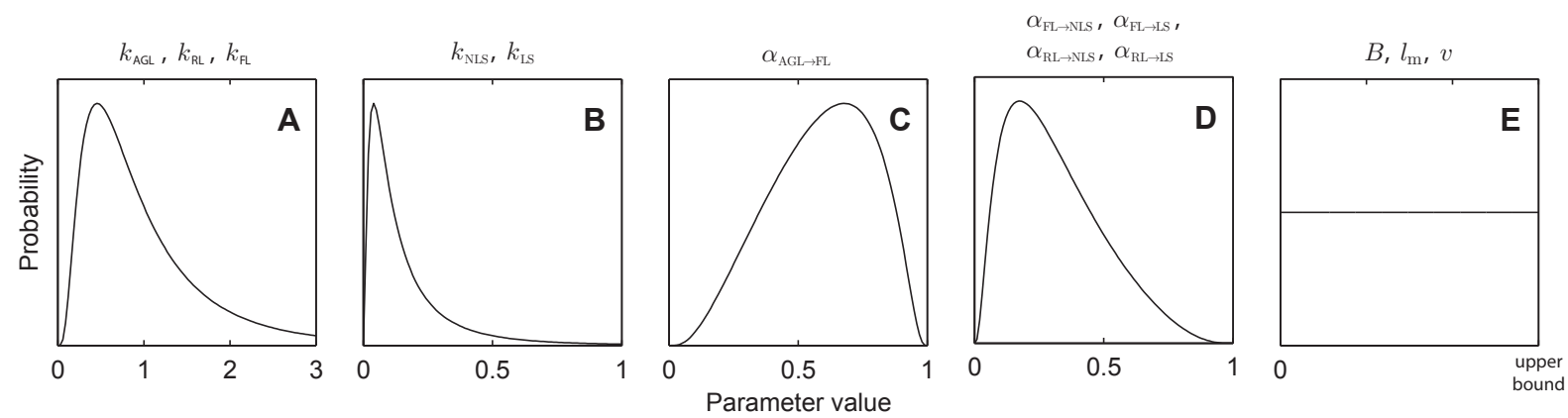

Fig. 3. Prior probability distributions of the model parameters used for calibration setup 3. See Table 2 for the parameters of the distribution functions. All distributions have a lower bound at zero and an upper bound which is given in Table 2 .

For the runs with strong priors, the distributions were based on knowledge from previously published studies (Braakhekke et al., 2011). The same distributions were used for both sites. Since decomposition rate coefficients cannot be negative or zero, we chose a log-normal distribution. For the litter pools $\left(k_{\mathrm{AGL}}, k_{\mathrm{RL}}\right.$ and $\left.k_{\mathrm{FL}}\right)$, we used the same distributions (mode at $0.46 \mathrm{yr}^{-1}$; Fig. 3a). It is likely that the decomposition rate coefficient of leachable slow organic matter $\left(k_{\mathrm{LS}}\right)$ is lower than that of non-leachable slow organic matter $\left(k_{\mathrm{NLS}}\right)$, since the former is comprised mostly of material adsorbed to the mineral phase. Nevertheless, since we aimed to test this hypothesis with the measurements, we used the same prior distributions for the decomposition rate coefficient of both pools (mode at $0.04 \mathrm{yr}^{-1}$; Fig. 3b).

We used logit-normal prior distributions for the transformation fractions. This distribution is similar to the beta distribution and is bounded between 0 and 1 (Mead, 1965). For $\alpha_{\text {AGL } \rightarrow \text { FL }}$ a distribution with the mode at 0.68 was used (Fig. 3c), while for the other conversion fractions ( $\alpha_{\mathrm{RL} \rightarrow \mathrm{NLS}}$, $\alpha_{\mathrm{RL} \rightarrow \mathrm{LS}}, \alpha_{\mathrm{FL} \rightarrow \mathrm{NLS}}$, and $\left.\alpha_{\mathrm{FL} \rightarrow \mathrm{LS}}\right)$ the same prior was used with the mode at 0.18 (Fig. 3d). Since relatively little a priori information about the SOM transport parameters $\left(B, l_{\mathrm{m}}\right.$, and $v$ ) is available, we used uniform priors for all calibrations (Fig. 3e).

For all calibration setups, the sampling was constrained to a bounded region in parameter space. This constraint was included since preliminary runs showed that some parameters may be unconstrained at the upper bound by the data, due to over-parameterization. The lower bounds for all parameters were set to zero; the upper bounds are listed in Table 2. Additionally, since decomposition must not lead to a net formation of material, the sum of transformation fraction for root litter $\left(\alpha_{\mathrm{RL} \rightarrow \mathrm{NLS}}+\alpha_{\mathrm{RL} \rightarrow \mathrm{LS}}\right)$ and fragmented litter $\left(\alpha_{\mathrm{FL} \rightarrow \mathrm{NLS}}+\alpha_{\mathrm{FL} \rightarrow \mathrm{LS}}\right)$ pools was bounded to 1 .

\subsubsection{Monte Carlo simulations}

The complexity of SOMPROF precludes analytical model inversion or expression of the normalizing constant in Eq. (6). Therefore, we approximated the posterior distribution using a Markov chain Monte Carlo algorithm. Such algorithms obtain a sample of the posterior distribution by performing a random walk through parameter space. They are increasingly used for calibrating ecosystem models against eddy-covariance measurements and satellite data (Knorr and Kattge, 2005; Fox et al., 2009) and have been applied to calibrate soil carbon models as well (Yeluripati et al., 2009; Scharnagl et al., 2010; de Bruijn and Butterbach-Bahl, 2010). We used the Metropolis algorithm DREAM(ZS) (Laloy and Vrugt, 2012), a successor to DREAM (Vrugt et al., 2009), which has been shown to perform well for complex, multimodal distributions . Further information concerning the calibration setup can be found in Appendix A1.

Additionally, we performed forward Monte Carlo simulations based on the posterior distributions. Five thousand simulations were made with parameter sets selected at regular intervals from the posterior sample. For these simulations, the non-leachable slow (NLS) and leachable slow (LS) organic matter pools were split into fractions originating from fragmented litter (FL) and root litter (RL), in order to trace the source of organic matter. Otherwise, the setup of the simulations was the same as those made for the calibration runs.

To study the importance of root litter input, bioturbation, and liquid phase transport for the formation of the SOM profile, the contribution of these processes was quantified. We estimated the amount of organic carbon that would be derived from these three processes for the steady state, giving an indication of their importance for long time scales. Note that the organic carbon derived from root litter input also includes material that is transformed from root litter to the slow pools, NLS and LS. Furthermore, bioturbation and liquid phase transport can lead to a net loss of organic matter at a given depth, as opposed to root litter input, which only leads to gain. Thus, the amount of organic carbon derived from the transport processes may be negative for certain depths. However, the sum of three organic carbon fractions must be positive. Further description of these calculations is given in Appendix B. 


\section{Results}

\subsection{Loobos}

Figure 4 depicts the marginal posterior distributions for the three calibrations for Loobos (see also Supplement Table 2).

For calibration setups 1 and 2, several parameters have wide distributions compared to the sampling range, which shows they are poorly constrained by the observations. Furthermore, for some of the parameters $\left(k_{\mathrm{RL}}, \alpha_{\mathrm{FL} \rightarrow \mathrm{LS}}\right.$, $\alpha_{\mathrm{RL} \rightarrow \mathrm{NLS}}, l_{\mathrm{m}}$, and $v$ ) the highest density point appears to lie at or near the upper or lower bound. Adding ${ }^{210} \mathrm{~Pb}_{\mathrm{ex}}$ improved the constraint of the bioturbation-related parameters ( $B$ and $l_{\mathrm{m}}$ ) but had otherwise no major effect on the marginal distributions. Inclusion of prior knowledge reduced uncertainty, particularly for the parameters that are poorly constrained by the data.

The results of the forward simulations (Fig. 5a, additional results shown in Supplement Fig. 4) indicate that leachable slow organic matter (LS) is the most abundant pool, followed by non-leachable slow organic matter (NLS). LS particularly dominates the mineral soil, being virtually the only pool below $20 \mathrm{~cm}$. Figure $5 \mathrm{~b}$ shows that most organic matter in the mineral soil is derived from root litter, but aboveground-derived SOM is present up to great depths, due to fast downward migration by liquid phase transport. Figure 6 a shows the organic matter transport fluxes in the mineral soil. Clearly, transport due to bioturbation plays almost no role; virtually all transport occurs by movement with the liquid phase. Figure $6 \mathrm{~b}$, which depicts the amount of organic carbon in the steady state derived from the three processes, corroborates the importance of liquid phase transport. The negative concentrations for this process indicate it causes organic matter from near the surface - mainly root litter derived - to be moved downward to greater depths, where it is the dominant mechanism of input.

\subsection{Hainich}

For Hainich, the posterior distribution is multi-modal for all calibration setups, comprising three distinct optima. For analysis, the modes were sampled individually in separate calibration runs. An additional calibration run was performed in which all modes were sampled simultaneously to assure that the multi-modality is not an artifact of the sampling (see Supplement Fig. 3). The marginal distributions for all calibration setups and all modes are depicted in Fig. 7 (see also Supplement Table 2). While the distributions of most parameters differ between the modes, the most prominent differences can be seen for the decomposition rate coefficients of root litter $\left(k_{\mathrm{RL}}\right)$, non-leachable slow $\left(k_{\mathrm{NLS}}\right)$, and leachable slow $\left(k_{\mathrm{LS}}\right)$ organic matter. For each of the modes, one of these three parameters is tightly constrained at the low end of the range, while the other two have wide distributions at higher values.
Addition of ${ }^{210} \mathrm{~Pb}_{\mathrm{ex}}$ to the observations caused shifts and reduction of uncertainty for some parameters (e.g., $v$ for mode A, $l_{\mathrm{m}}$ for mode B), but had in general no major effects on the posterior. Changing from weak to strong priors reduced uncertainty for parameters that are poorly constrained by the observations.

The comparative probability of the modes cannot be inferred from Fig. 7, since the distributions are scaled to the same height. To compare the modes we introduce the "misfit" $S(\boldsymbol{\theta})$ as the negative logarithm of the unnormalized posterior density (Mosegaard and Sambridge, 2002):

$$
S(\boldsymbol{\theta})=-\ln (p(\boldsymbol{\theta}) p(\boldsymbol{O} \mid \boldsymbol{\theta}))=-\ln (p(\boldsymbol{\theta}))-\sum_{i=1}^{I} \ln \left(S S_{i}(\boldsymbol{\theta})\right),
$$

where $\mathrm{SS}_{i}(\boldsymbol{\theta})$ is defined according to Eq. (9). A lower misfit indicates a higher posterior density and a better fit to the observations and priors. Note that the contribution of a single data stream to $S(\boldsymbol{\theta})$ may be negative for a high fit and/or small $N_{i}$. The modes are compared according to the lowest misfit in the calibration samples (Table 3). This shows that the three calibrations setups differ notably in terms of the comparative probability of the modes. In calibration 1 the three modes have similar misfit. Introduction of ${ }^{210} \mathrm{~Pb}_{\mathrm{ex}}$ and prior information to the calibration caused the misfit of mode $\mathrm{C}$ to increase markedly compared to $\mathrm{A}$ and $\mathrm{B}$, which is explained by a somewhat poorer fit to the ${ }^{210} \mathrm{~Pb}_{\mathrm{ex}}$ measurements (results not shown), as well as the very low root litter decomposition rate coefficient, which conflicts with prior knowledge.

Figure 8a depicts the simulated organic matter stocks and fractions of the three modes for calibration setup 3 (additional results are shown in Supplement Figs. 4 and 5). The different parameter values for the three modes give rise to quite different model results, despite the fact that the quantities of total organic matter are very similar and match the observations well. In each of the three modes, a different pool dominates the total stocks: non-leachable slow OM for mode A; leachable slow OM for mode B; and root litter for mode C. These contrasts are mainly explained by the differing decomposition rate coefficients of these three pools. Figure $8 \mathrm{~b}$ shows that modes $\mathrm{A}$ and $\mathrm{B}$ have very similar contributions of above- and belowground litter, whereas for mode $\mathrm{C}$ the root litter derived organic carbon is considerably larger. The differences between the modes are further demonstrated by the different organic matter transport fluxes (Fig. 9a). Interestingly, modes $\mathrm{A}$ and $\mathrm{C}$, which have the lowest amounts of the leachable slow organic matter pool, show the highest liquid phase transport fluxes, which is explained by the high advection rates. Figure $9 \mathrm{~b}$ shows that for all modes root litter input is an important process for long-term organic matter storage. For modes A and B most organic carbon is present as the slow pools NLS and LS derived from root litter, while for mode C RL itself is stable. The effects of the transport processes are generally smaller than those of root litter input. 

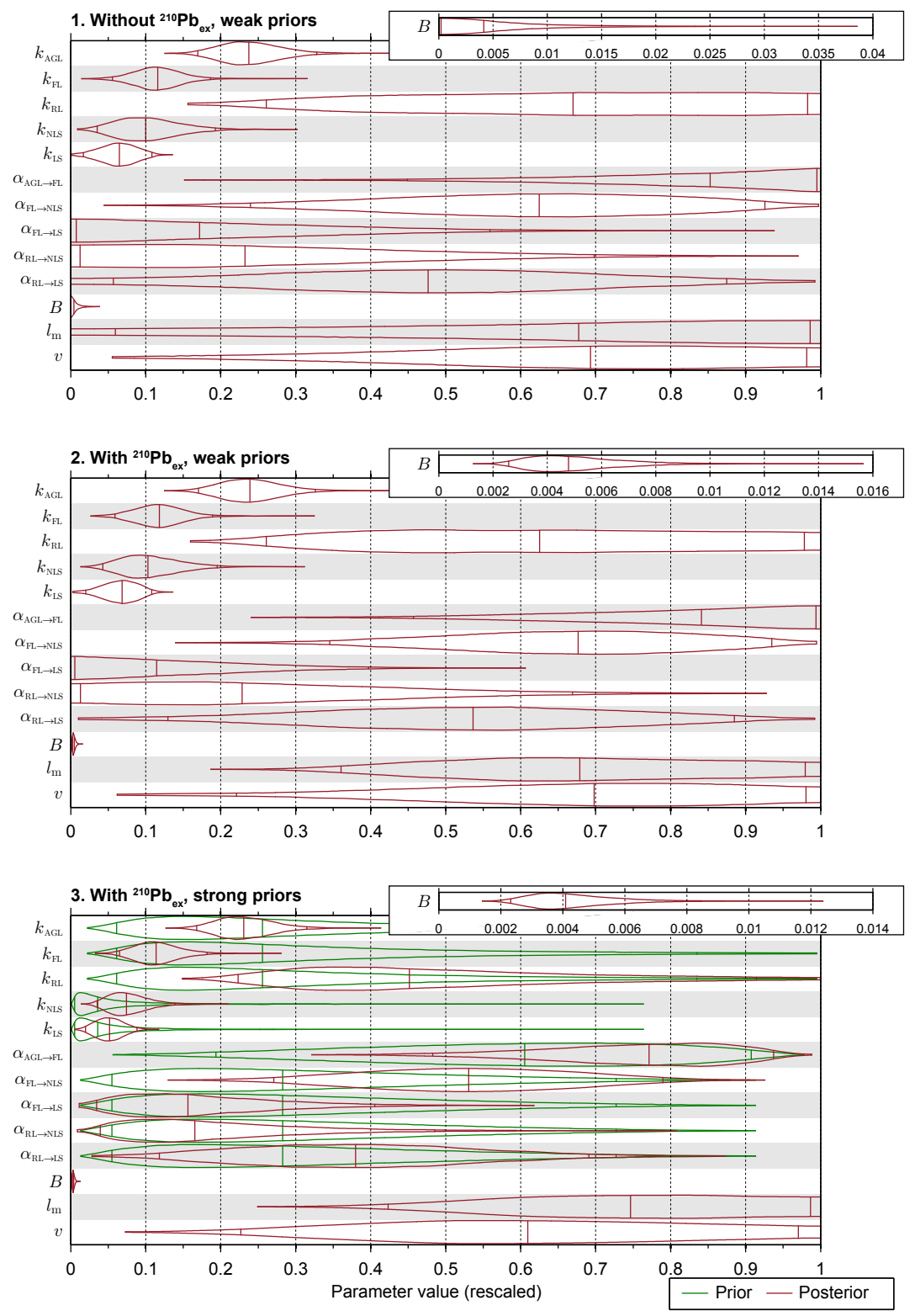

Fig. 4. Posterior distributions for the three setups for Loobos. The "violins" depict the marginal distribution for each parameter. The three vertical lines inside the violins indicate the median and the $95 \%$ confidence bounds. The parameters are normalized to the sampling ranges (see Table 2).

However, they represent an important mechanism for moving organic matter from shallow levels to deeper layers, as indicated by the negative values near the surface.

\section{Discussion}

\subsection{Loobos}

The calibration results for Loobos suggest that leachable slow (LS) OM is the most abundant organic matter fraction. Its transport with the liquid phase, representing dissolved or- ganic matter leaching, is largely responsible for downward SOM movement and formation of the vertical SOM profile in general. Although the decomposition rate coefficient of this pool $\left(k_{\mathrm{LS}}\right)$ is the lowest, its distribution tends to quite high values (optimum approximately $0.189 \mathrm{yr}^{-1}$ in calibration setup 3; Fig. 4c; Supplement Table 2). Particularly considering that LS is the only pool in the deep soil, where decomposition is slow, we would expect a lower value for $k_{\mathrm{LS}}$. The prior distribution of this parameter used in calibration setup 3, which tends to lower values, caused only a slight downward shift in the posterior. Due to its large variance, the 
(a) Soil organic matter pools

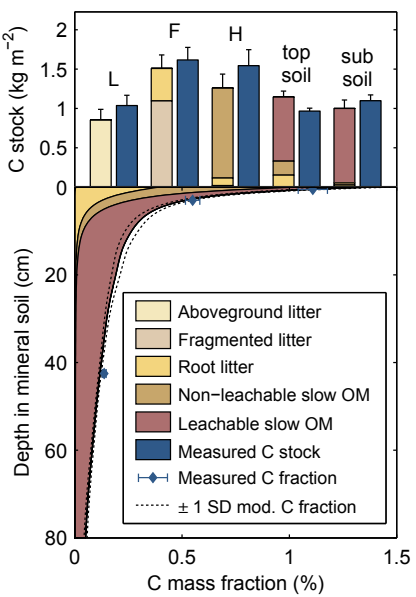

(b) Above/belowground derived soil organic carbon

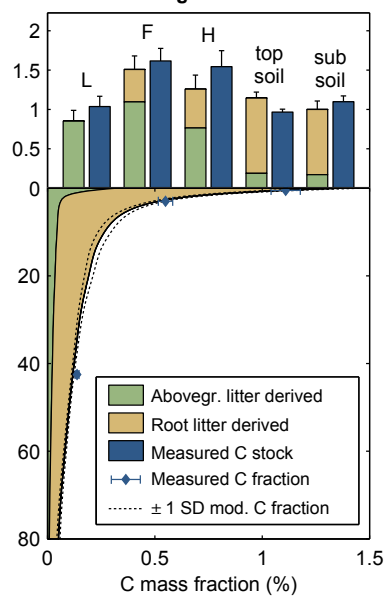

Fig. 5. Organic carbon measurements and corresponding model results of forward Monte Carlo simulations for Loobos, based on posterior distribution of calibration setup 3. (a) Stocks and fractions of the model pools; (b) above- vs. belowground derived organic matter. L, F, and $\mathrm{H}$ refer to the organic horizons (see Sect. 2.1); topsoil: 0-30 cm; subsoil: > $30 \mathrm{~cm}$; OM: organic matter. All model results are averages over the Monte Carlo ensemble; error bars denote one standard error of the mean for the measurements and one standard deviation (SD) for the model results.

Table 3. Minimum misfit value (see Eq. 11) in the posterior sample for each of the modes for Hainich for the three calibration setups. Note that the misfit values of calibration setup 2 are lower than those of calibration setup 1 . This is caused by the fact that the misfit values for the ${ }^{210} \mathrm{Pbex}$ are negative due to the small number of data points (cf. Eq. 10).

\begin{tabular}{lrrr}
\hline Calibration setup & Mode A & Mode B & Mode C \\
\hline $\begin{array}{l}\text { 1: Excl. }{ }^{210} \mathrm{~Pb}_{\mathrm{ex}} ; \\
\text { weak priors }\end{array}$ & 140.14 & 140.31 & 141.87 \\
$\begin{array}{l}\text { 2: Incl. }{ }^{210} \mathrm{~Pb}_{\mathrm{ex}} ; \\
\text { weak priors }\end{array}$ & 131.27 & 129.43 & 135.04 \\
$\begin{array}{l}\text { 3: Incl. }{ }^{210} \mathrm{~Pb} \\
\text { strong priors }\end{array}$ & 146.56 & 142.9 & 157.57 \\
\hline
\end{tabular}

posterior distribution of $k_{\mathrm{LS}}$ does allow for somewhat lower, more realistic values. Furthermore, there are quite strong correlations between parameters related to the LS pool (Supplement Fig. 6), which indicate that a decrease of the formation of LS (determined by $\alpha_{\mathrm{FL} \rightarrow \mathrm{LS}}$ and $\alpha_{\mathrm{RL} \rightarrow \mathrm{LS}}$ ) can be compensated by a decrease of the liquid phase transport rate $v$ or the decomposition rate coefficient $k_{\mathrm{LS}}$, both controlling the loss of this pool.

Although SOMPROF was not developed to simulate dissolved organic matter transport, the modeled liquid phase transport fluxes should represent the average movement of
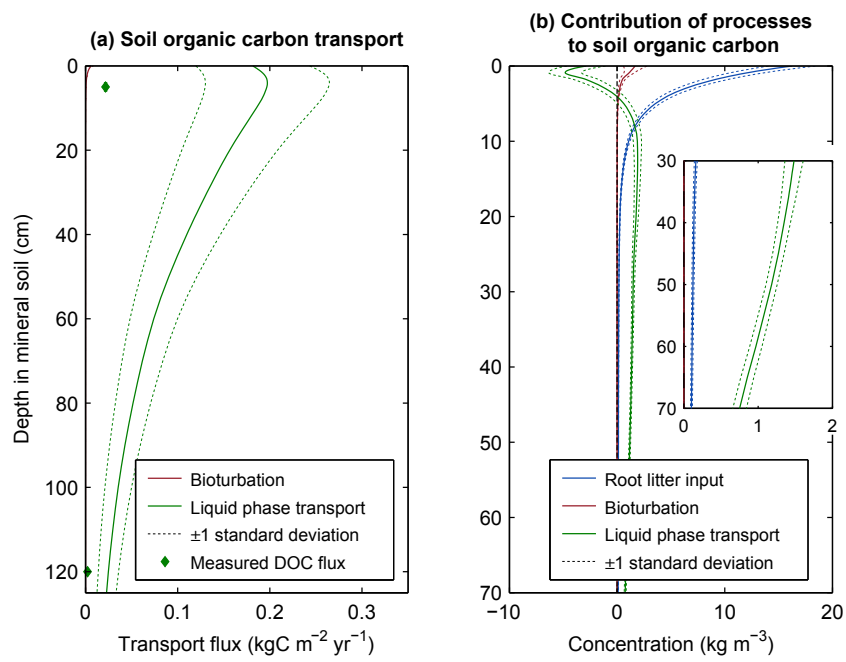

Fig. 6. Simulated organic carbon fluxes from forward Monte Carlo simulations for Loobos, based on posterior distribution of calibration setup 3 (note the different scales on the y-axes). All quantities are averages over the last simulation year and the Monte Carlo ensemble. (a) Organic carbon transport fluxes and measured dissolved organic carbon (DOC) fluxes (Kindler et al., 2011; not used in the calibration). Note the indistinct bioturbation flux in the upper left corner. (b) Contributions of the different processes to soil organic matter profile in mineral soil (see Sect. 2.4.3).

dissolved organic carbon (DOC) over long timescales ${ }^{1}$. Figure 6a shows that simulated liquid phase transport fluxes are an order of magnitude higher than DOC fluxes measured by Kindler et al. (2011), which points to a too high value of the advection rate $v$. However, the high uncertainty of both the rate and fluxes of liquid phase transport shows that the observations used in the calibration can also be explained with somewhat lower values. A lower value for $v$ would be accompanied by a lower decomposition rate coefficient of LS, since the two parameters are strongly correlated (Supplement Fig. 6). Thus, it is likely that additional observations constraining the deep soil decomposition rate coefficient, such as radiocarbon measurements, would lead to a more realistic estimate of liquid phase transport rate.

Notwithstanding the over-estimated liquid phase transport fluxes, the relative importance of organic matter leaching over bioturbation is in good agreement with the soil conditions and humus form at Loobos. Soil fauna is virtually absent, and the high concentration of sand supports fast water infiltration and has a low adsorptive capacity, thus allowing high dissolved organic matter fluxes.

\footnotetext{
${ }^{1}$ While the LS pool represents mostly material adsorbed to the mineral phase, the transport of this pool occurs only by the small fraction that is mobile and thus corresponds to DOC fluxes.
} 


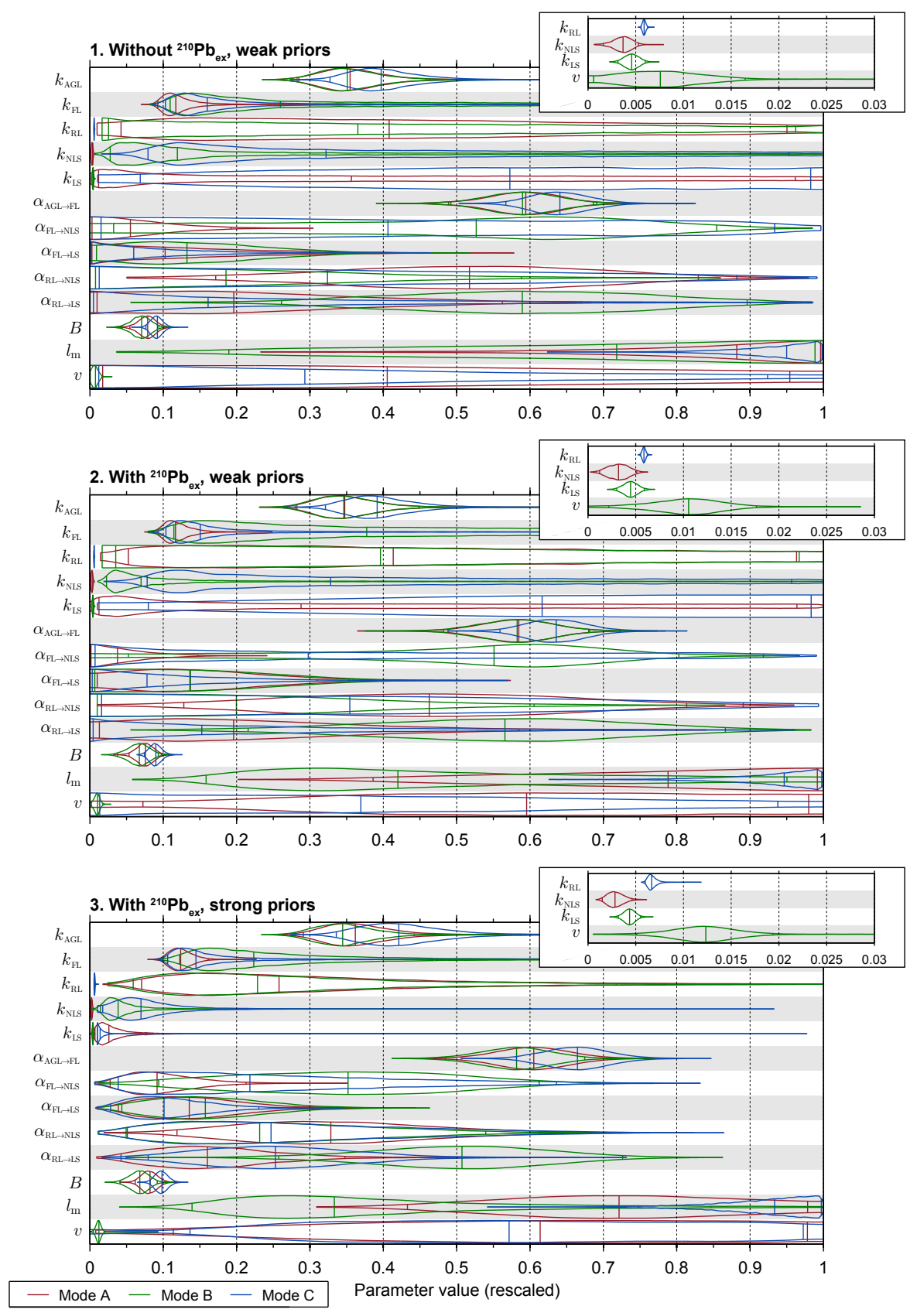

Fig. 7. Posterior distributions for the three calibration setups for Hainich. The "violins" depict the marginal distribution for each parameter. The three posterior modes are plotted separately in the same graph. The three vertical lines inside the violins indicate the median and the $95 \%$ confidence bounds. The parameters are normalized to the sampling ranges (see Table 2).

\subsection{Hainich}

The presence of multiple modes in the posterior distributions for Hainich is illustrative of the equifinality problem discussed in the introduction. Since the modes represent separate isolated regions in parameter space, they may be seen as distinct explanations for the observations, in terms of the processes represented in the model. In calibration setup 1 the three modes have similar misfits (Table 3 ). The addition of ${ }^{210} \mathrm{~Pb}_{\mathrm{ex}}$ to the calibration leads to a shift in the comparative misfit, causing mode B to become dominant. Switching to strong priors further increased these differences. Based on these results we can discard mode $\mathrm{C}$ with some certainty. The difference between modes $\mathrm{A}$ and $\mathrm{B}$, however, is relatively small. Hence, in view of unconsidered uncertainties 

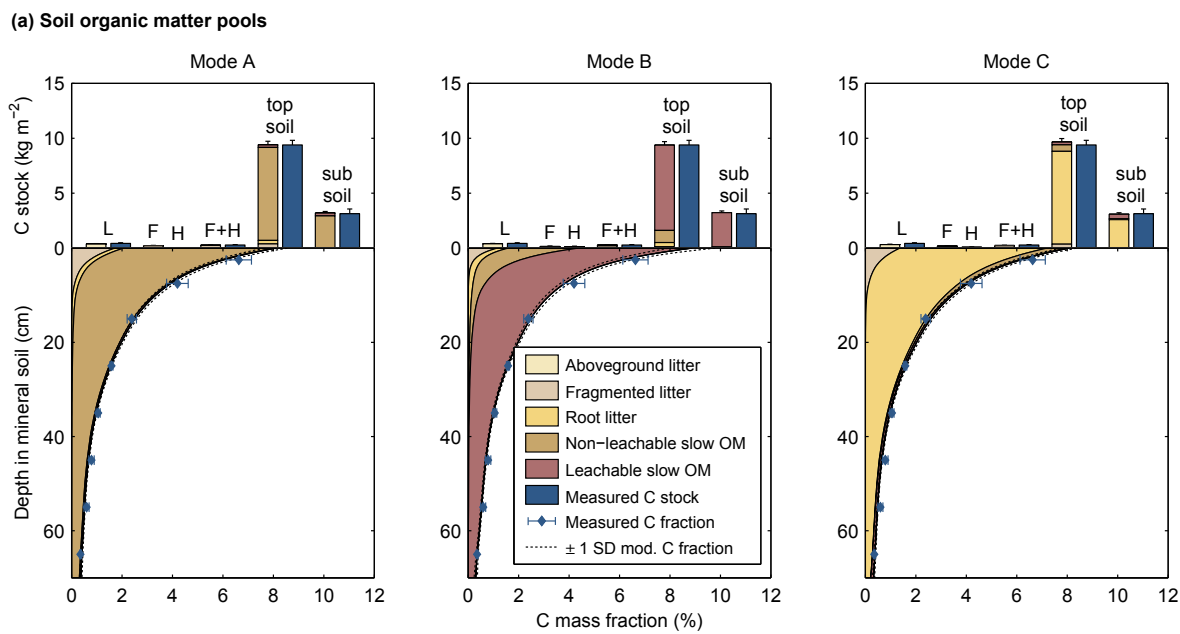

(b) Above/belowground derived soil organic carbon
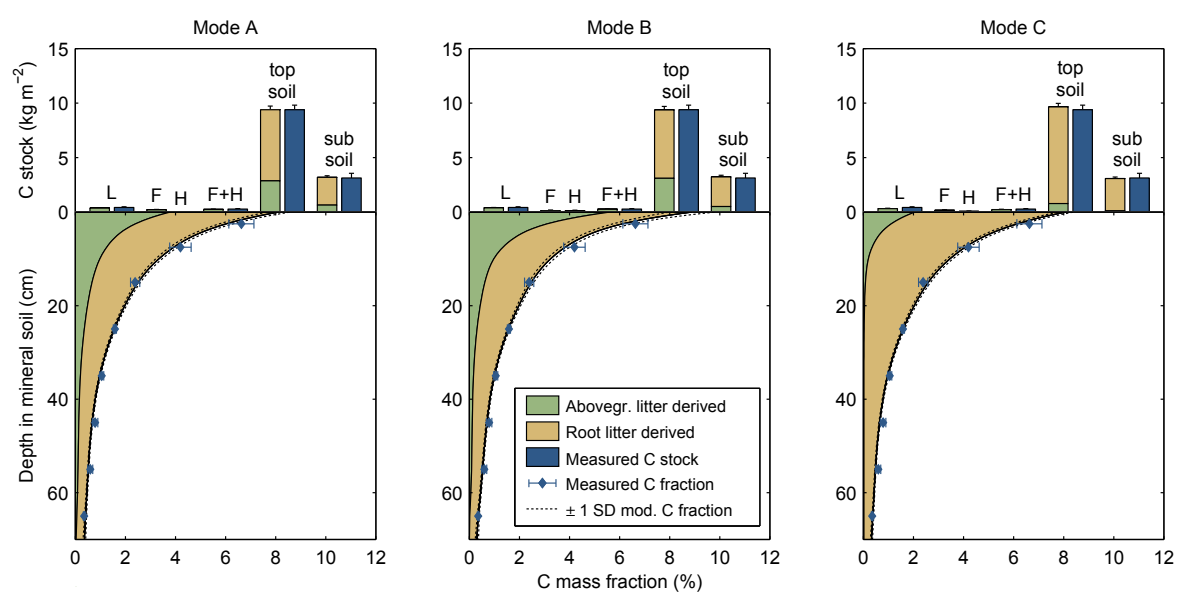

Fig. 8. Organic carbon measurements and corresponding model results of forward Monte Carlo simulations for Hainich, based on the three posterior modes of calibration setup 3. (a) Stocks and fractions of the model pools; (b) above- vs. belowground derived organic matter. L, F, and $\mathrm{H}$ refer to the organic horizons (see Sect. 2.1); topsoil: 0-30 cm; subsoil: $>30 \mathrm{~cm}$; OM: organic matter. All model results are averages over the Monte Carlo ensemble; error bars denote one standard error of the mean for the measurements and one standard deviation (SD) for the model results.

(see Sect. 4.6) we cannot fully ignore mode A as possible explanation for the observations.

Figure 9a shows that for all modes the modeled advective flux is substantially larger than the DOC fluxes measured by Kindler et al. (2011). However, for mode B the overestimation is less pronounced, particularly in the subsoil. For modes $\mathrm{A}$ and $\mathrm{C}$, modeled advective flux and its uncertainty are very high. Contrastingly, the contribution of advection to input in the profile is very small and well constrained for both modes (Fig. 9b). The reason is that the advective fluxes have relatively small vertical gradients. This also explains the high uncertainty of the advective flow (and the advection rate $v$ ) for these modes: as long as its gradient does not change, the actual flux can vary relatively freely.

The abundance of LS and the low rate of liquid phase transport for mode B agrees well with expectations based on the soil texture at Hainich. The high clay content im- pedes water infiltration, while favoring adsorption of organic matter, slowing down both dissolved organic matter leaching and decomposition of organic matter. This is corroborated by organic matter density fractionation measurements at the site (Schrumpf, 2011). These indicate that $81-93 \%$ of the organic matter is present in the heavy fraction, which is known to comprise mostly material in organo-mineral complexes (Golchin et al., 1994). Although the model pools can presumably not be compared directly to the measured density fractions, this is clearly in support of mode B, since leachable slow OM represents mostly material adsorbed to the mineral phase (Sect. 2.1.2; Braakhekke et al., 2011). Based on these arguments, we conclude that mode B represents the most likely explanation for the observations at Hainich.

The results of the forward simulations for mode B (Figs. 8 and 9) suggest that root input is the most important process at Hainich. Although root litter itself represents only a small 
(a) Soil organic carbon transport
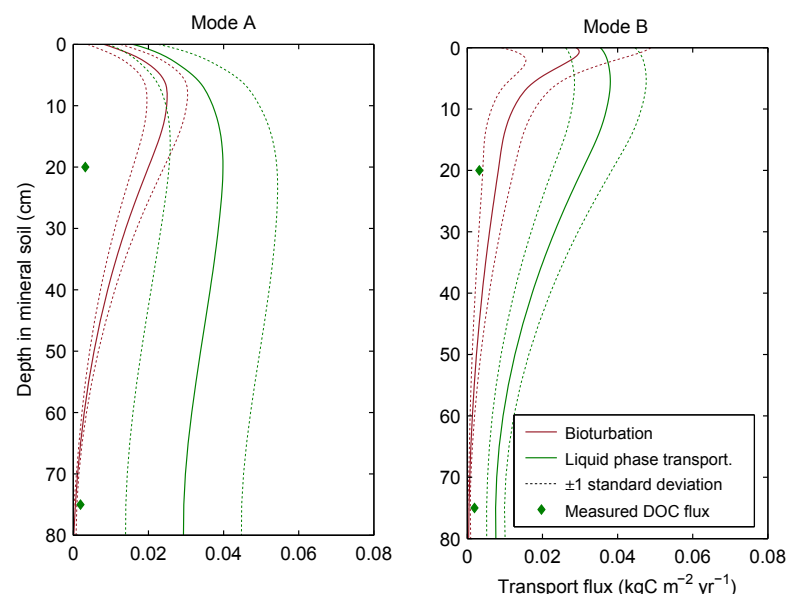

(b) Contribution of processes to soil organic carbon

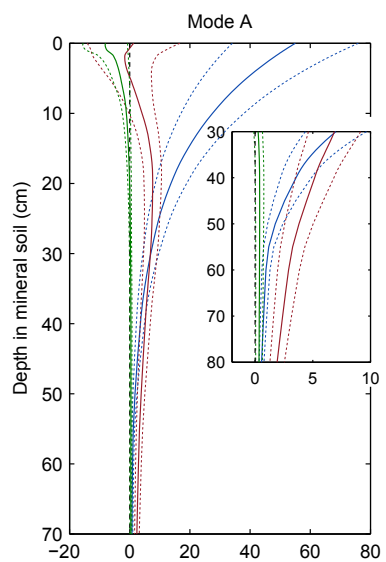

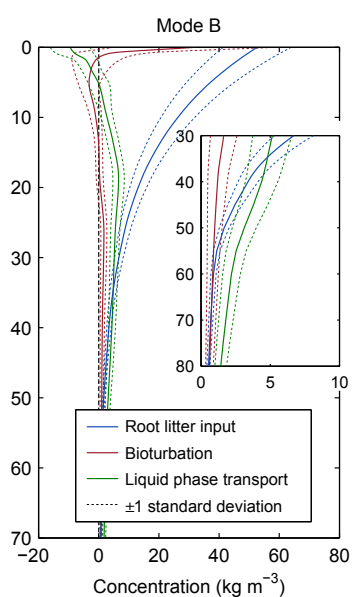
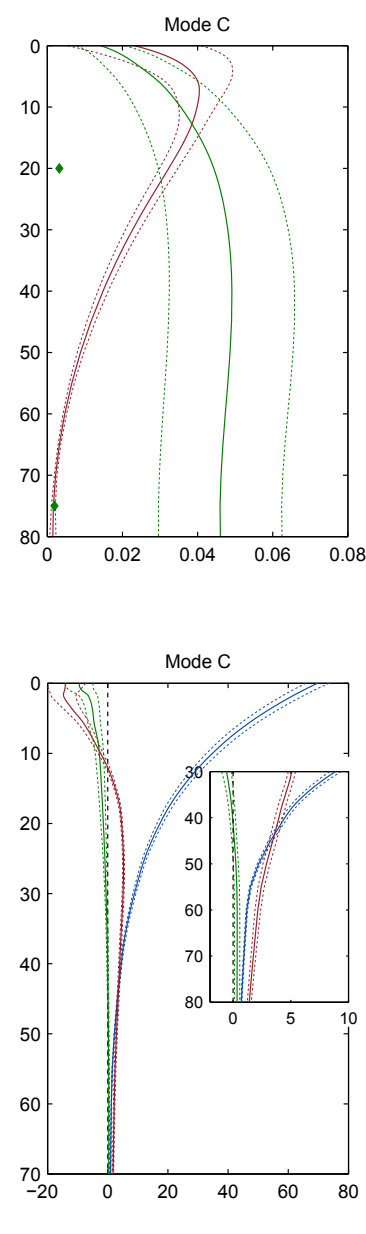

Fig. 9. Simulated organic carbon fluxes from forward Monte Carlo simulations for Hainich, based on the three modes of the posterior distribution of calibration setup 3 (note the different scales on the y-axes). All quantities are averages over the last simulation year and the Monte Carlo ensemble. (a) Organic carbon transport fluxes and measured dissolved organic carbon (DOC) fluxes (Kindler et al., 2011; not used in the calibration); (b) contribution of the different processes to soil organic matter profile in mineral soil (see Sect. 2.4.3).

fraction, its decomposition products (mainly LS) constitute the bulk of the total SOM. The effects of the transport processes are generally small compared to material derived from root litter input. However, particularly advection causes loss of material near the surface, and input into deeper layers. The relative importance of root-derived SOM agrees well with recent findings by Tefs and Gleixner (2012), who found, based on ${ }^{14} \mathrm{C}$ profile measurements, that soil organic carbon dynamics at Hainich are mainly determined by root input.

\subsection{Comparison between sites}

It is difficult to explain why the posterior distributions for Loobos do not display multi-modality, like the distributions for Hainich. One possible explanation is the fact that the observed mineral soil C profile for Loobos clearly consists of two zones: one with a fast decrease with depth between 0 and $10 \mathrm{~cm}$, and one below this, with a much slower decrease. It is conceivable that such a profile can only be explained by a situation where diffusion (bioturbation) operates only near the surface, while advection (liquid phase transport) acts in the complete profile. For Hainich, on the other hand, the C profile is smoother, thus allowing it to be explained by different mechanisms.

In the following discussion we will only consider mode B for Hainich. When comparing the marginal parameter distributions for both sites (see Supplement Fig. 7), it is apparent that the decomposition rates of the AGL and FL pools are higher for Hainich than for Loobos, while the reverse is true for RL, NLS, and LS. This agrees well with expectations: the low $\mathrm{pH}$ of the coniferous litter at Loobos may slow decomposition in the organic layer; hence we can expect the pools that are important there to have low decomposition rates. On the other hand, the high clay content at Hainich likely stabilizes organic matter in the mineral soil, leading to lower 
decomposition rates of the pools that dominate there. Comparison further shows that the decomposition rate coefficient of the main pool LS is markedly lower for Hainich, and much less uncertain. This is presumably explained by the observations of the effective decomposition rate coefficients. For the deep soil these data directly constrain the decomposition rate coefficient of LS since this is virtually the only pool there (see also Supplement Fig. 5). In view of the considerable effort involved with such measurements, a study into the value of such data for inferring SOMPROF parameters would be valuable. However, in general care must be taken when using lab measurements to infer parameters for field conditions. Furthermore, for the decomposition rate coefficients of the slow pools, very long incubation times may be required (Scharnagl et al., 2010).

The two sites differ strongly with respect to the organic matter transport parameters, with Hainich having a higher bioturbation rate, and Loobos having a higher liquid phase transport rate. This is in good agreement with the differences between the two sites in terms of biological activity and soil texture.

\subsection{Implications for soil organic matter cycling}

The fact that leachable slow organic matter pool constitutes the bulk of SOM for both sites emphasizes the importance of organo-mineral interactions for soil carbon cycling. However, this interpretation relies on the assumption that mineralassociated organic matter is correctly represented by the LS pool. Mathematically, the only difference between the NLS and LS pools lies in the transport behavior: diffusion-only versus diffusion and advection. The question is whether this distinction correctly represents the differences between stable particulate and adsorbed organic matter in reality. The good agreement of our results with density fractionation measurements at Hainich, as well as the environmental conditions at both sites, suggests that an explanation where LS dominates might indeed be appropriate. Furthermore, many studies have demonstrated the importance of mineral associations for long-term carbon preservation (Eusterhues et al., 2003; Mikutta et al., 2006; Kögel-Knabner et al., 2008; Kalbitz and Kaiser, 2008). In contrast, others have indicated the presence of root-derived particulate material in podzol B horizons, and questioned the relevance of mineral-associated material for mineral soil organic matter fractions (Nierop, 1998; Nierop and Buurman, 1999; Buurman and Jongmans, 2005).

The predominance of root-derived material predicted for both sites (Figs. 5 and 8, mode B) underlines the importance of roots for organic matter input in the mineral soil, which is in agreement with previous studies (Kong and Six, 2010; Rasse et al., 2005). For Hainich, the root input also strongly determines the vertical distribution of SOM (Fig. 9), whereas for Loobos also redistribution of organic material by liquid phase transport is a major factor (Fig. 6). Based on analy- sis of a large database of SOM profiles, Jobbagy and Jackson (2000) found that root/shoot allocation, together with the root biomass distribution, explains the vertical SOM profile in the upper part of the soil while clay content was found to be more important at greater depths. The effects of texture are not considered in this study, but Figs. $6 \mathrm{~b}$ and $9 \mathrm{~b}$ show that the relative importance of liquid phase transport becomes greater with depth. This supports the findings of Jobbagy and Jackson (2000) since this mechanism is likely strongly controlled by soil texture.

\subsection{The use of ${ }^{210} \mathrm{~Pb}_{\mathrm{ex}}$ measurements}

The addition of ${ }^{210} \mathrm{~Pb}_{\mathrm{ex}}$ to the calibration had no major effects on the posterior distributions. For Loobos, the ${ }^{210} \mathrm{~Pb}_{\mathrm{ex}}$ measurements improved the constraint of the parameters related to bioturbation, while for Hainich they improved constraint of the mixing length for mode $\mathrm{B}$, and caused an increase of the misfit of mode $B$ and $C$ relative to mode $A$. The fact that the ${ }^{210} \mathrm{~Pb}_{\mathrm{ex}}$ data influenced only parameters related to bioturbation may be explained by the fact that the profiles used here are quite shallow, due to the relatively fast decay rate of the isotope (cf. Fig. 2). These measurements are therefore presumably most informative for the topsoil, where bioturbation is more important.

For both sites, the measured ${ }^{210} \mathrm{~Pb}_{\mathrm{ex}}$ profile was already well matched by the model in calibration setup 1 , in which these measurements were not included. This indicates that these observations can be explained well in conjunction with the organic carbon measurements, which supports the model structure. It also suggests that the ${ }^{210} \mathrm{~Pb}_{\mathrm{ex}}$ data from Kaste et al. (2007) are consistent with the conditions at Loobos.

The use of ${ }^{210} \mathrm{~Pb}_{\mathrm{ex}}$ as a tracer for $\mathrm{SOM}$ transport relies on the assumption that $\mathrm{Pb}$ adsorbs strongly to organic matter, both particulate and in solution. Based on ${ }^{210} \mathrm{~Pb}_{\mathrm{ex}}$ and ${ }^{14} \mathrm{C}$ profiles, Dörr and Münnich (1989) found that transport rates of ${ }^{210} \mathrm{~Pb}_{\mathrm{ex}}$ were very close to those of organic matter, suggesting that the two are indeed strongly linked. Although $\mathrm{Pb}$ is known to occur also in association with the mineral phase and inorganic complexes (Schroth et al., 2008), the affinity of $\mathrm{Pb}$ to particulate organic matter is well established, in view of its strong retention in organic layers and topsoils over short timescales (Kaste et al., 2003; Kylander et al., 2008; Schroth et al., 2008), as well as by adsorption studies (Logan et al., 1997; Sauve et al., 2000). The effect of DOM movement on $\mathrm{Pb}$ migration is less clear, because it is difficult to predict the behavior of $\mathrm{Pb}$ adsorbed to the organic matter that is transformed to the dissolved fraction. Several researchers have indicated the importance of DOM and colloidal organic matter for $\mathrm{Pb}$ movement in soil (Miller and Friedland, 1994; Wang and Benoit, 1997; Urban et al., 1990; Friedland et al., 1992). Furthermore, adsorption studies have found that $\mathrm{Pb}$ adsorbs readily to humic and fulvic acids (Logan et al., 1997; Turner et al., 1986), 
while movement of dissolved $\mathrm{Pb}^{2+}$ was found to be unimportant (Wang and Benoit, 1997).

In summary, further study on this topic is needed, but we believe that use of ${ }^{210} \mathrm{~Pb}_{\mathrm{ex}}$ as a tracer for $\mathrm{SOM}$ transport is well defendable. Despite the limited constraint gained in this study, this isotope can be useful as a tracer for SOM transport, provided that more replicate measurements are available to reduce uncertainty. Particularly in combination with other tracers, such as ${ }^{14} \mathrm{C}$ or ${ }^{137} \mathrm{Cs},{ }^{210} \mathrm{~Pb}_{\mathrm{ex}}$ may be quite informative.

\subsection{Methodological constraints and model validity}

For both sites, many strong correlations exist between different combinations of model parameters (Supplement Fig. 6), which indicates that the model is over-parameterized with respect to the available data. Furthermore, for all calibration setups there is at least one decomposition rate coefficient for which high values are not constrained by the observations (Figs. 4 and 7). Since the predicted stock of a pool is inversely proportional to its decomposition rate coefficient, these pools are present in very small amounts, which shows that SOMPROF has at least one redundant organic matter pool, given the available data. This is further demonstrated by a strong negative correlation between decomposition rate coefficient of FL and RL for Loobos (Supplement Fig. 6), indicating that these pools are essentially "competing" as explanation for the observed carbon stocks and fractions. In order to obtain better constraint, additional observations are needed. Obvious candidates for such data are carbon isotopes $\left({ }^{13} \mathrm{C}\right.$ or $\left.{ }^{14} \mathrm{C}\right)$ measurements, of both organic matter and heterotrophic respiration.

There are numerous uncertainties that were not considered in the calibration. In view of practical limitations on the number of parameters that can be estimated simultaneously, we focused on the inherently unmeasurable parameters, on which little prior information was available. Many other model inputs, with varying degrees of uncertainty, were held fixed, including the temperature and moisture data, the litter input rates, and the temperature and moisture response parameters. Another source of uncertainty is associated with site history. The sites included in this study were selected for having a relatively well-known and constant history, but particularly for Hainich there have undoubtedly been past fluctuations in the forcing that were not considered. Finally, considerable uncertainty is related to the model structure, specifically to the simple representations of organic matter decomposition and transport in SOMPROF as well as the behavior of ${ }^{210} \mathrm{~Pb}_{\mathrm{ex}}$. These unconsidered variabilities call for care when interpreting the results. Further, it may be advisable to inflate the variance of the posterior distributions when using them as priors for a follow-up study, or for predictive simulations. Nevertheless, we believe that the parameters that were estimated constitute the most important uncertainties.
The good fit to the observations indicates that SOMPROF is able to reproduce widely different SOM profiles, based on realistic parameter values. Furthermore, the consistency of the results with site conditions and the good fit to the ${ }^{210} \mathrm{~Pb}_{\mathrm{ex}}$ measurements (even when they are not included in the calibration) are encouraging and support the validity of SOMPROF for temperate forests. The validity for other ecosystems such as grasslands and tropical and boreal forests is yet to be established. Also, comparison to other types of measurements is needed, both to improve constraint of the processes, and to further evaluate the model. Examples of such data include carbon isotopes, heterotrophic respiration rates, and chronosequence measurements. The strong overestimation of advective flux compared measured DOC flux rates suggests the need for modifications to the transport scheme. Addition of the DOC measurements to the calibration should reveal if the model can reproduce these data with acceptable loss of fit for the other observations. If not, it may be necessary to introduce depth dependence of the advection rate, for example by linking to average water fluxes and soil texture. Finally, further study should explore whether simplification of the model by removal of organic matter pools is warranted. If so, a possible modification would involve merging the root litter and fragmented litter pools, which are functionally very similar.

\section{Concluding remarks}

In order to study the processes involved in SOM profile formation, we performed Bayesian estimation of SOMPROF model parameters for Loobos and Hainich, based on organic carbon and ${ }^{210} \mathrm{~Pb}_{\mathrm{ex}}$ measurements as well as prior knowledge. The final calibration yielded a multi-modal posterior distribution for Hainich, with two dominant modes corresponding to two distinct explanations for the observations. One mode was found to be most realistic in light of ancillary measurements, and in situ soil conditions. For Loobos, the posterior distribution is unimodal.

For both Loobos and the most probable mode for Hainich, most of the organic matter is comprised of the leachable slow organic matter pool, which represents material that is mostly adsorbed, but potentially leachable. The results further indicate that for both sites most organic matter in the mineral soil is derived from root inputs. For Hainich, root input also determines the vertical distribution of SOM, whereas for Loobos downward advective movement of SOM, representing liquid phase transport, represents a major control. These results agree well with other measurements and in situ conditions.

The ${ }^{210} \mathrm{~Pb}_{\mathrm{ex}}$ measurements improved constraint of the parameters related to bioturbation and reduced the probability of one of the modes for Hainich, but had otherwise no major influence on the posterior distributions. Nevertheless, since the ${ }^{210} \mathrm{~Pb}_{\text {ex }}$ observations could be reproduced well together 
with the organic carbon measurements, we believe this isotope holds value as a SOM tracer.

Our study illustrates the difficulties with explaining the vertical SOM profile caused by the convolution of several mechanisms. Soil carbon profile measurements are necessary but in general not sufficient for resolving the processes. Ancillary measurements such as respiration rates or tracers are needed, and even then the model may remain over-parameterized. Bayesian calibration using Markov chain Monte Carlo is an invaluable tool for such problems since it helps to identify (non-linear) parameter correlations and the existence of multiple modes, which with traditional calibration tools could easily have gone unnoticed. Furthermore, inclusion of prior knowledge mitigates the adverse effects of over-parameterization.

For future large-scale application of SOMPROF, sets of characteristic parameter values for different soils and ecosystems are required. With results of the current study and future calibrations, progressively stronger prior distributions can be derived, which can be used for sites where fewer observations are available.

\section{Appendix A}

\section{Markov chain Monte Carlo scheme}

\section{A1 The Metropolis algorithm}

The Metropolis algorithm (Metropolis et al., 1953) samples the posterior distribution by means of a Markov chain, which performs a random walk in parameter space. At each iteration $i$ proposals of the parameters $\boldsymbol{\theta}^{*}$ are generated by taking a (semi-)random step from the current position $\boldsymbol{\theta}^{i}$. The model is run with the proposed parameter set, and the unnormalized posterior probability density $(p(\boldsymbol{\theta}) p(\boldsymbol{O} \mid \boldsymbol{\theta}))$ of the proposal is evaluated. The proposal is subsequently accepted or rejected according to the Metropolis rule, which defines the chance for acceptance as:

$s=\min \left\{\frac{p\left(\boldsymbol{O} \mid \boldsymbol{\theta}^{*}\right) p\left(\boldsymbol{\theta}^{*}\right) \lambda\left(\boldsymbol{\theta}^{*}\right)}{p\left(\boldsymbol{O} \mid \boldsymbol{\theta}^{i}\right) p\left(\boldsymbol{\theta}^{i}\right) \lambda\left(\boldsymbol{\theta}^{i}\right)}, 1\right\}$,

where $\lambda(\boldsymbol{\theta})$ is a factor that may be included to remove the effects of sampling in transformed parameter space (see Sect. A2). The decision for acceptance or rejection is made using a random number from a uniform distribution on the unit interval. In case of acceptance, the chain moves to the position of the proposal; in case of rejection the chain stays at the current position, which is thus sampled again.

We used the DREAM(ZS) algorithm (Laloy and Vrugt, 2012), an adaptation of the DREAM (DiffeRential Evolution Adaptive Metropolis) algorithm that uses multiple chains in parallel and automatically adapts the scale and orientation of the proposal distribution.

\section{A2 Parameter transformations}

Since calibration algorithms generally perform better for distributions that are close to Gaussian, the random walk performed was in transformed parameter space for all calibration setups. For the decomposition rate coefficients $\left(k_{i}\right)$ and transport rates $\left(B, l_{\mathrm{m}}, v\right)$, a log transformation was applied

$\theta^{\prime}=\ln (\theta)$,

and for the transformation fractions $\alpha_{i \rightarrow j}$ a logit transformation was used:

$\theta^{\prime}=\operatorname{logit}(\theta)=\ln \left(\frac{\theta}{1-\theta}\right)$,

where $\theta^{\prime}$ is the transformed parameter value and $\theta$ is the untransformed parameter value, used as input for SOMPROF.

From the rules for change of variables for probability density functions, it follows that performing the random walk in transformed space affects the sampled distribution. Suppose we apply Monte Carlo sampling according to some density function $(f(\theta))$ and our samples $\left(\theta^{\prime}\right)$ are generated in transformed space according to $\theta^{\prime}=g(\theta)$. Then our sampled target distribution will be:

$\tau(\theta) \propto\left|\frac{\mathrm{d}}{\mathrm{d} \theta} g(\theta)\right| f(\theta)$.

The factor in vertical bars is the Jacobian of the transformation or inverse transformation, depending on what is the scale of interest. This effect was removed by multiplying the posterior density by the reciprocal of the Jacobian, which is the factor $(\lambda(\theta))$ in Eq. (A1). For a log transformation:

$\lambda(\theta)=\theta$,

and for a logit transformation:

$\lambda(\theta)=\theta-\theta^{2}$.

\section{A3 Calibration setup}

For each calibration first an exploratory run was performed, intended to search for different posterior modes. For this run, at least 20 chains were run in parallel, with starting points widely dispersed in the sampling region using Latin hypercube sampling. Furthermore, the posterior cost was reduced using a cost-reduction factor of 0.1 , multiplied with the log posterior density. This effectively "flattens" the posterior, allowing the chains to escape from local modes and to take bigger steps, thus covering more area. After all modes of interest were identified in the exploratory run, secondary runs without cost reduction were performed with eight chains, started near each mode.

The convergence of the chains was evaluated using the Gelman-Rubin index (Gelman et al., 2004, Chap. 11), which 
is proportional to the ratio of the between-chain variance and the within-chain variance, and declines to 1 when different chains converge on the same distribution. All chains were run until the convergence index was $\leq 1.01$ for all parameters, with at least 100000 iterations per chain.

After the secondary runs, a variable number of iterations was removed from the start of each chain (the burn-in). Next, the remaining chains for each mode were merged and thinned to 10000 iterations for analysis by selecting iterations in regular intervals. The continuous posterior distributions depicted in the Figs. 4 and 7 were derived using kernel density estimation.

\section{Appendix B}

\section{Calculation of process contributions to the SOM profile}

In SOMPROF there are five processes that cause input or redistribution of the organic matter pools in the mineral soil (see Fig. 1): root litter input (RLI), formation due to fragmented litter decomposition (FLdec), formation due to root litter decomposition (RLdec), bioturbation (BT), and liquid phase transport (LPT). Obviously, not every organic matter pool is influenced by each process. The average fluxes (in $\mathrm{kg} \mathrm{C} \mathrm{m}^{-3} \mathrm{yr}^{-1}$ ) over the last simulation year of these processes are calculated by SOMPROF in the forward Monte Carlo runs, yielding the following flux rates: $F_{\mathrm{FL}}^{\mathrm{BT}}, F_{\mathrm{RL}}^{\mathrm{RLI}}$, $F_{\mathrm{RL}}^{\mathrm{BT}}, F_{\mathrm{NLS}}^{\mathrm{FLdec}}, F_{\mathrm{NLS}}^{\mathrm{RLdec}}, F_{\mathrm{NLS}}^{\mathrm{BT}}, F_{\mathrm{LS}}^{\mathrm{FLdec}}, F_{\mathrm{LS}}^{\mathrm{RLdec}}, F_{\mathrm{LS}}^{\mathrm{BT}}$, and $F_{\mathrm{LS}}^{\mathrm{LPT}}$. Note that the net input/output of organic matter due to bioturbation/diffusion and liquid phase transport/advection are not equal to the flux rates of these processes (as depicted in Figs. 6a and 9a), but are defined as the vertical derivative of the transport fluxes. For a system with discrete layers, this means the difference between the flux at the top and at the bottom of a layer. The relative importance of each of these fluxes for long-term SOM storage may be estimated by dividing them by the decomposition rate coefficient of the respective pools, yielding an organic carbon concentration for the steady state $\left(\mathrm{kg} \mathrm{C} \mathrm{m}^{-3}\right)$ :

$C_{i}^{j}=\frac{F_{i}^{j}}{k_{i}}$

for any pool $i$ and process $j$. Since root litter at any depth may come from either root litter input or bioturbation, also the decomposition products of root litter (NLS and LS) may be split into fractions that come from these two sources:

$$
\begin{gathered}
C_{\mathrm{NLS}}^{\mathrm{RLdec}, \mathrm{RLI}}=\frac{C_{\mathrm{RL}}^{\mathrm{RLI}}}{C_{\mathrm{RL}}^{\mathrm{RLI}}+C_{\mathrm{RL}}^{\mathrm{BT}}} C_{\mathrm{NLS}}^{\mathrm{RLdec}}, \\
C_{\mathrm{NLS}}^{\mathrm{RLdec}, \mathrm{BT}}=\frac{C_{\mathrm{RL}}^{\mathrm{BT}}}{C_{\mathrm{RL}}^{\mathrm{RL}}+C_{\mathrm{RL}}^{\mathrm{BT}}} C_{\mathrm{NLS}}^{\mathrm{RLdec}},
\end{gathered}
$$

$C_{\mathrm{LS}}^{\mathrm{RLdec}, \mathrm{RLI}}=\frac{C_{\mathrm{RL}}^{\mathrm{RLI}}}{C_{\mathrm{RL}}^{\mathrm{RLI}}+C_{\mathrm{RL}}^{\mathrm{BT}}} C_{\mathrm{LS}}^{\mathrm{RLdec}}$,

$C_{\mathrm{LS}}^{\mathrm{RL}, \mathrm{BT}}=\frac{C_{\mathrm{RL}}^{\mathrm{BT}}}{C_{\mathrm{RL}}^{\mathrm{RL}}+C_{\mathrm{RL}}^{\mathrm{BT}}} C_{\mathrm{LS}}^{\mathrm{RLdec}}$.

The calculations above yield 12 carbon concentrations: $C_{\mathrm{FL}}^{\mathrm{BT}}, C_{\mathrm{RL}}^{\mathrm{RLI}}, C_{\mathrm{RL}}^{\mathrm{BT}}, C_{\mathrm{NLS}}^{\mathrm{FLdec}}, C_{\mathrm{NLS}}^{\mathrm{RLdec}, \mathrm{RLI}}, C_{\mathrm{NLS}}^{\mathrm{RLdec}, \mathrm{BT}}, C_{\mathrm{NLS}}^{\mathrm{BT}}$, $C_{\mathrm{LS}}^{\mathrm{FLdec}}, C_{\mathrm{LS}}^{\mathrm{RLdec}, \mathrm{RLI}}, C_{\mathrm{LS}}^{\mathrm{RLdec}, \mathrm{BT}}, C_{\mathrm{LS}}^{\mathrm{BT}}$, and $C_{\mathrm{LS}}^{\mathrm{LPT}}$. Note that the sum of these concentrations is not necessarily equal to the simulated total concentration, because (i) the simulated SOM profile may not be in steady state, and (ii) the effects of soil temperature and moisture are not accounted for when estimating the steady-state concentration. However, since all the pools respond equally to soil temperature and moisture, the relative distribution of the organic matter over the pools is correct for the steady state.

To quantify the importance of the three processes root litter input, bioturbation and liquid phase transport, the organic carbon concentrations are summed as follows:

$$
\begin{aligned}
C^{\mathrm{RLI}} & =C_{\mathrm{RL}}^{\mathrm{RLI}}+C_{\mathrm{NLS}}^{\mathrm{RLdec}, \mathrm{RLI}}+C_{\mathrm{LS}}^{\mathrm{RLec}, \mathrm{RLI}}, \\
C^{\mathrm{BT}} & =C_{\mathrm{FL}}^{\mathrm{BT}}+C_{\mathrm{RL}}^{\mathrm{BT}}+C_{\mathrm{NLS}}^{\mathrm{BT}}+C_{\mathrm{NLS}}^{\mathrm{FLdec}}+C_{\mathrm{NLS}}^{\mathrm{RLdec}, \mathrm{BT}} \\
& +C_{\mathrm{LS}}^{\mathrm{RLdec}, \mathrm{BT}}+C_{\mathrm{LS}}^{\mathrm{FLdec}}+C_{\mathrm{LS}}^{\mathrm{BT}}, \\
C^{\mathrm{LPT}} & =C_{\mathrm{LS}}^{\mathrm{LPT} .}
\end{aligned}
$$

Since the transport processes may also cause loss of organic matter at a given depth, their contributions to the total organic carbon may also be negative. However, the sum over all contributions must be positive and equal to the total steady-state organic carbon concentration for a simulation with temperature and moisture constant at $15^{\circ} \mathrm{C}$ and optimal soil moisture.

\section{Supplementary material related to this article is available online at: http://www.biogeosciences.net/10/ 399/2013/bg-10-399-2013-supplement.pdf.}

Acknowledgements. We are obliged to Jim Kaste and Ryoko Fujiyoshi for providing the ${ }^{210} \mathrm{~Pb}_{\mathrm{ex}}$ data used in the calibrations, Wilma Jans, Jan Elbers, Ivan Janssens, and Enrico Weber for supplying data and information on Loobos, and Jasper Vrugt for the code of the DREAM(ZS) algorithm. Finally, we thank A. de Bruijn, M. van Oijen, B. Scharnagl, and two anonymous reviewers for providing helpful comments on the earlier versions of this manuscript. This work was supported by the ERC starting 
grant QUASOM (ERC-2007-StG-208516).

The service charges for this open access publication

have been covered by the Max Planck Society.

Edited by: F. Carswell

\section{References}

Appleby, P. G. and Oldfield, F.: The calculation of lead-210 dates assuming a constant rate of supply of unsupported ${ }^{210} \mathrm{~Pb}$ to the sediment, Catena, 5, 1-8, 1978.

Arai, H. and Tokuchi, N.: Factors contributing to greater soil organic carbon accumulation after afforestation in a Japanese coniferous plantation as determined by stable and radioactive isotopes, Geoderma, 157, 243-251, 2010.

Baisden, W. T., Amundson, R., Brenner, D. L., Cook, A. C., Kendall, C., and Harden, J. W.: A multiisotope $\mathrm{C}$ and $\mathrm{N}$ modeling analysis of soil organic matter turnover and transport as a function of soil depth in a California annual grassland soil chronosequence, Global Biogeochem. Cy., 16, 1135, doi:10.1029/2001GB001823, 2002.

Beven, K. and Freer, J.: Equifinality, data assimilation, and uncertainty estimation in mechanistic modelling of complex environmental systems using the GLUE methodology, J. Hydrol., 249, 11-29, 2001.

Bormann, F. and Likens, G.: Pattern and Process in a Forested Ecosystem: Disturbance, Development, and the Steady State Based on the Hubbard Brook Ecosystem Study, Springer-Verlag, New York, 1994.

Boudreau, B. P.: Mathematics of tracer mixing in sediments; I, Spatially-dependent, diffusive mixing, Am. J. Sci., 286, 161198, 1986.

Braakhekke, M. C., Beer, C., Hoosbeek, M. R., Reichstein, M., Kruijt, B., Schrumpf, M., and Kabat, P.: SOMPROF: A vertically explicit soil organic matter model, Ecol. Model., 222, 17121730, 2011.

Burden, R. L.: Numerical analysis, Belmont, California, Brooks/Cole, 8th edn., 2004.

Buurman, P. and Jongmans, A. G.: Podzolisation and soil organic matter dynamics, Geoderma, 125, 71-83, 2005.

Cesarz, S., Fahrenholz, N., Migge-Kleian, S., Platner, C., and Schaefer, M.: Earthworm communities in relation to tree diversity in a deciduous forest, Eur. J. Soil Biol., 43, 61-67, 2007.

de Bruijn, A. M. G. and Butterbach-Bahl, K.: Linking carbon and nitrogen mineralization with microbial responses to substrate availability - the DECONIT model, Plant Soil, 328, 271-290, 2010.

Dörr, H. and Münnich, K. O.: Downward movement of soil organic matter and its influence on trace-element transport $\left({ }^{210} \mathrm{~Pb}\right.$, ${ }^{137} \mathrm{Cs}$ ) in the soil, Radiocarbon, 31, 655-663, 1989.

Dörr, H. and Münnich, K. O.: Lead and cesium transport in european forest soils, Water Air Soil Poll., 57, 809-818, 1991.

Elzein, A. and Balesdent, J.: Mechanistic simulation of vertical distribution of carbon concentrations and residence times in soils, Soil Sci. Soc. Am. J., 59, 1328-1335, 1995.

Emmer, I. M.: Humus form and soil development during a primary succession of monoculture Pinus sylvestris on poor sandy soils, Ph. D. thesis, University of Amsterdam, Amsterdam, 1995.
Eusterhues, K., Rumpel, C., Kleber, M., and Kögel-Knabner, I.: Stabilisation of soil organic matter by interactions with minerals as revealed by mineral dissolution and oxidative degradation, Org. Geochem., 34, 1591-1600, 2003.

Federer, C. A., Turcotte, D. E., and Smith, C. T.: The organic fraction - bulk density relationship and the expression of nutrient content in forest soils, Can. J. For. Res.-Rev., 23, 1026-1032, 1993.

Fox, A., Williams, M., Richardson, A. D., Cameron, D., Gove, J. H., Quaife, T., Ricciuto, D., Reichstein, M., Tomelleri, E., Trudinger, C. M., and Van Wijk, M. T.: The REFLEX project: Comparing different algorithms and implementations for the inversion of a terrestrial ecosystem model against eddy covariance data, Agr. Forest Meteorol., 149, 1597-1615, 2009.

Freier, K. P., Glaser, B., and Zech, W.: Mathematical modeling of soil carbon turnover in natural Podocarpus forest and Eucalyptus plantation in Ethiopia using compound specific delta ${ }^{13} \mathrm{C}$ analysis, Glob. Change Biol., 16, 1487-1502, 2010.

Friedland, A. J., Craig, B. W., Miller, E. K., Herrick, G. T., Siccama, T. G., and Johnson, A. H.: Decreasing lead levels in the forest floor of the Northeastern USA, Ambio, 21, 400-403, 1992.

Fujiyoshi, R. and Sawamura, S.: Mesoscale variability of vertical profiles of environmental radionuclides (K-40, Ra-226, Pb-210 and Cs-137) in temperate forest soils in Germany, Sci. Total Environ., 320, 177-188, 2004.

Gelman, A., Carlin, J. B., Stern, S., and Rubin, D. B.: Bayesian data analysis, Chapman and Hall, 2004.

Golchin, A., Oades, J. M., Skjemstad, J. O., and Clarke, P.: Soilstructure and carbon cycling, Aust. J. Soil Res., 32, 1043-1068, 1994.

He, Q. and Walling, D. E.: The distribution of fallout Cs-137 and $\mathrm{Pb}-210$ in undisturbed and cultivated soils, Appl. Radiat. Isotopes, 48, 677-690, 1997.

Heimann, M. and Reichstein, M.: Terrestrial ecosystem carbon dynamics and climate feedbacks, Nature, 451, 289-292, 2008.

IUSS Working Group WRB: World Reference Base for Soil Resources 2006, first update 2007, Tech. rep., FAO, 2007.

Janssens, I. A., Sampson, D. A., Curiel-Yuste, J., Carrara, A., and Ceulemans, R.: The carbon cost of fine root turnover in a Scots pine forest, Forest Ecol. Manag., 168, 231-240, 2002.

Jenkinson, D. S. and Coleman, K.: The turnover of organic carbon in subsoils. Part 2. Modelling carbon turnover, Eur. J. Soil Sci., 59, 400-413, 2008.

Jobbagy, E. G. and Jackson, R. B.: The vertical distribution of soil organic carbon and its relation to climate and vegetation, Ecol. Appl., 10, 423-436, 2000.

Kaiser, K. and Guggenberger, G.: The role of DOM sorption to mineral surfaces in the preservation of organic matter in soils, Org. Geochem., 31, 711-725, 2000.

Kalbitz, K. and Kaiser, K.: Contribution of dissolved organic matter to carbon storage in forest mineral soils, J. Plant Nutr. Soil Sci., 171, 52-60, 2008.

Kaste, J. M., Friedland, A. J., and Sturup, S.: Using stable and radioactive isotopes to trace atmospherically deposited $\mathrm{Pb}$ in montane forest soils, Environ. Sci. Technol., 37, 3560-3567, 2003.

Kaste, J. M., Heimsath, A. M., and Bostick, B. C.: Short-term soil mixing quantified with fallout radionuclides, Geology, 35, 243246, 2007. 
Kindler, R., Siemens, J., Kaiser, K., Walmsley, D. C., Bernhofer, C., Buchmann, N., Cellier, P., Eugster, W., Gleixner, G., Grunwald, T., Heim, A., Ibrom, A., Jones, S. K., Jones, M., Klumpp, K., Kutsch, W., Larsen, K. S., Lehuger, S., Loubet, B., McKenzie, R., Moors, E., Osborne, B., Pilegaard, K., Rebmann, C., Saunders, M., Schmidt, M. W. I., Schrumpf, M., Seyfferth, J., Skiba, U., Soussana, J. F., Sutton, M. A., Tefs, C., Vowinckel, B., Zeeman, M. J., and Kaupenjohann, M.: Dissolved carbon leaching from soil is a crucial component of the net ecosystem carbon balance, Glob. Change Biol., 17, 1167-1185, 2011.

Knorr, W. and Kattge, J.: Inversion of terrestrial ecosystem model parameter values against eddy covariance measurements by Monte Carlo sampling, Glob. Change Biol., 11, 1333-1351, 2005.

Kögel-Knabner, I., Guggenberger, G., Kleber, M., Kandeler, E., Kalbitz, K., Scheu, S., Eusterhues, K., and Leinweber, P.: Organo-mineral associations in temperate soils: integrating biology, mineralogy, and organic matter chemistry, J. Plant Nutr. Soil Sci., 171, 61-82, 2008.

Kong, A. Y. Y. and Six, J.: Tracing root vs. residue carbon into soils from conventional and alternative cropping systems, Soil Sci. Soc. Am. J., 74, 1201-1210, 2010.

Koven, C., Friedlingstein, P., Ciais, P., Khvorostyanov, D., Krinner, G., and Tarnocai, C.: On the formation of high-latitude soil carbon stocks: effects of cryoturbation and insulation by organic matter in a land surface model, Geophys. Res. Lett., 36, L21501, doi:10.1029/2009GL040150, 2009.

Kutsch, W., Persson, T., Schrumpf, M., Moyano, F., Mund, M., Andersson, S., and Schulze, E.-D.: Heterotrophic soil respiration and soil carbon dynamics in the deciduous Hainich forest obtained by three approaches, Biogeochemistry, 100, 1-17, 2010.

Kylander, M. E., Cortizas, A. M., Rauch, S., and Weiss, D. J.: Lead penetration and leaching in a complex temperate soil profile, Environ. Sci. Technol., 42, 3177-3184, 2008.

Laloy, E. and Vrugt, J. A.: High-dimensional posterior exploration of hydrologic models using multiple-try DREAM(ZS) and high-performance computing, Water Resour. Res., 48, W01526, doi:10.1029/2011wr010608, 2012.

Lloyd, J. and Taylor, J. A.: On the temperature dependence of soil respiration, Funct. Ecol., 8, 315-323, 1994.

Logan, E. M., Pulford, I. D., Cook, G. T., and MacKenzie, A. B.: Complexation of $\mathrm{Cu}^{2+}$ and $\mathrm{Pb}^{2+}$ by peat and humic acid, Eur. J. Soil Sci., 48, 685-696, 1997.

Luyssaert, S., Inglima, I., Jung, M., Richardson, A. D., Reichstein, M., Papale, D., Piao, S. L., Schulze, E. D., Wingate, L., Matteucci, G., Aragao, L., Aubinet, M., Beer, C., Bernhofer, C., Black, K. G., Bonal, D., Bonnefond, J. M., Chambers, J., Ciais, P., Cook, B., Davis, K. J., Dolman, A. J., Gielen, B., Goulden, M., Grace, J., Granier, A., Grelle, A., Griffis, T., Grünwald, T., Guidolotti, G., Hanson, P. J., Harding, R., Hollinger, D. Y., Hutyra, L. R., Kolari, P., Kruijt, B., Kutsch, W., Lagergren, F., Laurila, T., Law, B. E., Le Maire, G., Lindroth, A., Loustau, D., Malhi, Y., Mateus, J., Migliavacca, M., Misson, L., Montagnani, L., Moncrieff, J., Moors, E., Munger, J. W., Nikinmaa, E., Ollinger, S. V., Pita, G., Rebmann, C., Roupsard, O., Saigusa, N., Sanz, M. J., Seufert, G., Sierra, C., Smith, M. L., Tang, J., Valentini, R., Vesala, T., and Janssens, I. A.: $\mathrm{CO}_{2}$ balance of boreal, temperate, and tropical forests derived from a global database, Glob. Change Biol., 13, 2509-2537, 2007.
Mabit, L., Klik, A., Benmansour, M., Toloza, A., Geisler, A., and Gerstmann, U. C.: Assessment of erosion and deposition rates within an Austrian agricultural watershed by combining Cs-137, $\mathrm{Pb}-210(\mathrm{ex})$ and conventional measurements, Geoderma, 150, 231-239, 2009.

Mead, R.: A generalised logit-normal distribution, Biometrics, 21, 721-732, 1965.

Metropolis, N., Rosenbluth, A. W., Rosenbluth, M. N., Teller, A. H., and Teller, E.: Equation of state calculations by fast computing machines, J. Chem. Phys., 21, 1087-1092, 1953.

Mikutta, R., Kleber, M., Torn, M. S., and Jahn, R.: Stabilization of soil organic matter: association with minerals or chemical recalcitrance?, Biogeochemistry, 77, 25-56, 2006.

Miller, E. K. and Friedland, A. J.: Lead migration in forest soils response to changing atmospheric inputs, Environ. Sci. Technol., 28, 662-669, 1994.

Mosegaard, K. and Sambridge, M.: Monte Carlo analysis of inverse problems, Inverse Probl., 18, 29-54, 2002.

Nierop, K. G. J.: Origin of aliphatic compounds in a forest soil, Org. Geochem., 29, 1009-1016, 1998.

Nierop, K. G. J. and Buurman, P.: Water-soluble organic matter in incipient podzols: accumulation in B horizons or in fibres?, Eur. J. Soil Sci., 50, 701-711, 1999.

Parton, W. J., Schimel, D. S., Cole, C. V., and Ojima, D. S.: Analysis of factors controlling soil organic matter levels in great plains grasslands, Soil Sci. Soc. Am. J., 51, 1173-1179, 1987.

Rasse, D. P., Rumpel, C., and Dignac, M.-F.: Is soil carbon mostly root carbon? Mechanisms for a specific stabilisation, Plant. Soil, 269, 341-356, 2005.

Reichstein, M. and Beer, C.: Soil respiration across scales: The importance of a model-data integration framework for data interpretation, J. Plant Nutr. Soil Sci., 171, 344-354, 2008.

Rumpel, C. and Kögel-Knabner, I.: Deep soil organic matter - a key but poorly understood component of terrestrial C cycle, Plant Soil, 338, 143-158, 2011.

Rumpel, C., Kögel-Knabner, I., and Bruhn, F.: Vertical distribution, age, and chemical composition of organic, carbon in two forest soils of different pedogenesis, Org. Geochem., 33, 1131-1142, 2002.

Salomé, C., Nunan, N., Pouteau, V., Lerch, T. Z., and Chenu, C.: Carbon dynamics in topsoil and in subsoil may be controlled by different regulatory mechanisms, Glob. Change Biol., 16, 416426, 2010.

Sauve, S., Martinez, C. E., McBride, M., and Hendershot, W.: Adsorption of free lead $\left(\mathrm{Pb}^{2+}\right)$ by pedogenic oxides, ferrihydrite, and leaf compost, Soil Sci. Soc. Am. J., 64, 595-599, 2000.

Scharnagl, B., Vrugt, J. A., Vereecken, H., and Herbst, M.: Information content of incubation experiments for inverse estimation of pools in the Rothamsted carbon model: a Bayesian perspective, Biogeosciences, 7, 763-776, doi:10.5194/bg-7-763-2010, 2010.

Schroth, A. W., Bostick, B. C., Kaste, J. M., and Friedland, A. J.: Lead sequestration and species redistribution during soil organic matter decomposition, Environ. Sci. Technol., 42, 3627-3633, 2008.

Schrumpf, M., Schulze, E. D., Kaiser, K., and Schumacher, J.: How accurately can soil organic carbon stocks and stock changes be quantified by soil inventories?, Biogeosciences, 8, 1193-1212, doi:10.5194/bg-8-1193-2011, 2011. 
Smit, A.: The impact of grazing on spatial variability of humus profile properties in a grass-encroached Scots pine ecosystem, Cate, 36, 85-98, 1999.

Smit, A. and Kooijman, A. M.: Impact of grazing on the input of organic matter and nutrients to the soil in a grass-encroached Scots pine forest, Forest Ecol. Manag., 142, 99-107, 2001.

Tefs, C. and Gleixner, G.: Importance of root derived carbon for soil organic matter storage in a temperate old-growth beech forest Evidence from C, $\mathrm{N}$ and ${ }^{14} \mathrm{C}$ content, Forest Ecol. Manag., 263, 131-137, 2012.

Tonneijck, F. H. and Jongmans, A. G.: The influence of bioturbation on the vertical distribution of soil organic matter in volcanic ash soils: a case study in Northern Ecuador, Eur. J. Soil Sci., 59, 1063-1075, 2008.

Trumbore, S.: Radiocarbon and Soil Carbon Dynamics, Ann. Rev. Earth Planet. Sci., 37, 47-66, 2009.

Tuomi, M., Thum, T., Järvinen, H., Fronzek, S., Berg, B., Harmon, M., Trofymow, J. A., Sevanto, S., and Liski, J.: Leaf litter decomposition - estimates of global variability based on Yasso07 model, Ecol. Model., 220, 3362-3371, 2009.

Turner, D. R., Varney, M. S., Whitfield, M., Mantoura, R. F. C., and Riley, J. P.: Electrochemical studies of copper and lead complexation by fulvic-acid. 1. potentiometric measurements and a critical comparison of metal-binding models, Geochim. Cosmochim. Ac., 50, 289-297, 1986.

Urban, N. R., Eisenreich, S. J., Grigal, D. F., and Schurr, K. T.: Mobility and diagenesis of $\mathrm{Pb}$ and $\mathrm{Pb}-210$ in peat, Geochim. Cosmochim. Ac., 54, 3329-3346, 1990.

Veresoglou, D. S. and Fitter, A. H.: Spatial and temporal patterns of growth and nutrient-uptake of 5 co-existing grasses, J. Ecol., 72, 259-272, 1984 von Lützow, M., Kögel-Knabner, I., Ekschmitt, K., Matzner, E., Guggenberger, G., Marschner, B., and Flessa, H.: Stabilization of organic matter in temperate soils: mechanisms and their relevance under different soil conditions - a review, Eur. J. Soil Sci., 57, 426-445, 2006.

Vrugt, J. A., ter Braak, C. J. F., Diks, C. G. H., Robinson, B. A., Hyman, J. M., and Higdon, D.: Accelerating Markov Chain Monte Carlo simulation by differential evolution with self-adaptive randomized subspace sampling, Int. J. Nonlin. Sci. Num., 10, 273 290, 2009.

Wakiyama, Y., Onda, Y., Mizugaki, S., Asai, H., and Hiramatsu, S.: Soil erosion rates on forested mountain hillslopes estimated using Cs-137 and Pb-210(ex), Geoderma, 159, 39-52, 2010.

Walling, D. E. and He, Q.: Using fallout lead-210 measurements to estimate soil erosion on cultivated land, Soil Sci. Soc. Am. J., 63, 1404-1412, 1999.

Wang, E. X. and Benoit, G.: Fate and transport of contaminant lead in spodosols: A simple box model analysis, Water Air Soil Poll., 95, 381-397, 1997.

WUR, Alterra: Loobos site, available at: http://www. climatexchange.nl/sites/loobos/index.htm, date retrieved: 08/03, 2011.

Yeluripati, J. B., van Oijen, M., Wattenbach, M., Neftel, A., Ammann, A., Parton, W. J., and Smith, P.: Bayesian calibration as a tool for initialising the carbon pools of dynamic soil models, Soil Biol. Biochem., 41, 2579-2583, 2009.

Yoo, K., Ji, J. L., Aufdenkampe, A., and Klaminder, J.: Rates of soil mixing and associated carbon fluxes in a forest versus tilled agricultural field: Implications for modeling the soil carbon cycle, J. Geophys. Res., 116, G01014, doi:10.1029/2010JG001304, 2011. 